\title{
EVOLUTION OF NATURAL DISASTER TERMINOLOGIES, WITH A CASE STUDY OF THE COVID-19 PANDEMIC
}

H. Jithamala Caldera ( $\sim$ jithamala.caldera@gmail.com )

University of Calgary Schulich School of Engineering https://orcid.org/0000-0001-8896-7846

S. C. Wirasinghe

University of Calgary Schulich School of Engineering

\section{Research Article}

Keywords: Disaster, Catastrophe, Emergency, Disaster Terminologies, Disaster Categorization, Severity Scale

Posted Date: February 23rd, 2022

DOl: https://doi.org/10.21203/rs.3.rs-1377556/v1

License: (a) (i) This work is licensed under a Creative Commons Attribution 4.0 International License. Read Full License 


\section{Abstract}

Emergency, disaster, catastrophe, calamity, and cataclysm are some of the terminologies that describe the nature and severity of adverse natural events. Civilians, reporters, and even professionals often use these terminologies for communication and reporting any event's severity as using this linguistic method is the most practical way during disasters to rapidly reach all levels of local, regional, national, and international stakeholder groups. Therefore, these disaster terminologies play a significant role in the disaster management field. However, attaining the actual magnitude of a disaster's severity cannot be comprehended simply by using this linguistic method because these terminologies are used interchangeably. Unfortunately, there is no consistent method to differentiate disaster terminologies from one another. Additionally, no globally accepted standard technique to communicate the level of severity of disasters exists; one observer's 'disaster' event can be another's 'catastrophic' event depending on their personal experience and knowledge. Hence, a nations' ability to manage extreme natural events is difficult when there are no agreed terminologies among emergency management systems. Thus, a standard severity classification system is required to understand, communicate, report, and educate stakeholders during ferocious natural events. This paper presents people's perceptions about disaster terminologies, rankings and differences in disaster lexicon (dictionary) meanings and lexical (verbal) meanings. It explores how people consider major events (e.g., the Covid-19 pandemic), and proposes a ranking of disaster terminologies to create a severity classification system suitable for use on a global level.

\section{Introduction}

The agreed terminology in quantifying 'disaster' matters. Because of inconsistency in how the various terminologies are perceived by stakeholders, the lack of agreed terminology poses a global challenge in formulating legislation and policies regarding disaster response (Yew et al. 2019). Failing to identify confusion or a potential hazard during disaster communication can lead to devastating consequences. For example, regarding Hurricane Katrina, Tierney (2008) explained that "... Katrina's devastating impacts were worsened by a sluggish and ineffective response by all levels of government and by a lack of leadership on the part of high-ranking federal government officials and others who were incapable of recognizing Katrina's catastrophic capability, even after the storm made landfall." In addition, inconsistent identification of disaster impacts results in overcompensation or under-compensation in assigning resources for mitigation. Overcompensation may waste resources, while under-compensation could increase the impact severity. Identifying the disaster impact properly and promptly is crucial because lives depend on these decisions (Caldera and Wirasinghe 2015a). Moreover, there are no national boundaries to these natural phenomena when they strike. Impacts of a disaster in a region, if not managed properly, can produce political and social instability and affect international security and relations (Olsen et al., 2003). The current Covid-19 pandemic is a good example of these consequences.

Therefore, a common communication platform is needed to convey vital information in a standard format that can be understood by a global audience. The linguistic method is the oldest method of describing natural disasters of various magnitudes. It is also the most used practical way to communicate and report during disasters because it will rapidly reach up to all levels of local, provincial, regional, national, continental, or international stakeholder groups. This method is also used for educational purposes for the same reason. Therefore, this linguistic method benefits many stakeholder groups such as emergency responders and disaster managers, insurance managers and estimators, national/regional/local governments, NGOs, local relief agencies, media outlets, the research community, reporters, and the general public. In addition, the foundation of any science is definition, classification, and measurement; if disaster management is to grow and progress effectively, it also must have a consistent and recognized definition, classification, and measurement system (de Boer 1990).

However, there is no globally accepted standard method to communicate the level of severity when natural disasters strike. To describe the severity level of a natural disaster, which can range from a small community fire to large-scale events, such as a tsunami or earthquake, terminologies such as "emergency," "disaster," and "catastrophe" are generally used. Though these terminologies imply increasing levels of severity, they are used interchangeably because these terminologies are more subjective than objective regarding disaster severity depending on the user's personal feelings, knowledge, and experience

Page $2 / 30$ 
regarding the event (Caldera and Wirasinghe 2014). Hence, obtaining a sense of the real magnitude of a disaster's severity is problematic and cannot be comprehended by merely using common descriptive terminologies because there are no consistent definitions, methods, or a clear sense of scale to distinguish one terminology from another (Caldera et al. 2016a).

Different stakeholder groups currently tend to use different measurement systems; these individual scales have been developed using the linguistic method to categorize the different levels of severity depending on specific groups' needs. For disaster, medical personnel, de Boer's (1990) classification is used with three levels (accident, calamity, and disaster) depending on causalities and required extra mobilization of medical resources and other resources. For emergency responders and disaster managers, Tierney's (2008) scale of severity with three levels (emergencies, disasters, and catastrophes) depends on both the impacts and the management challenges associated with response and recovery. Also, for the same group, the Encyclopedia of Crisis Management's classification (Penuel et al. 2013) with four levels (incidents, major incidents, disasters, and catastrophes). For information and database managers, the Munich RE global loss database (NatCatSERVICE) classification with six levels (small-scale loss event, moderate loss event, severe disaster, major disaster, devastating disaster, and great natural disaster) is used based on their loss profile and fatalities (Löw and Wirtz 2010). However, the terminologies and the criteria used to define different levels by the above classifications differ. These disconnected systems make it even harder to communicate among stakeholders about the severity of a disaster. Consequently, confusion occurs when reporting or communicating the severity of an event.

As a solution to the lack of uniformity and standardization in describing disaster events, common classification systems have been developed in the last 15 years for all stakeholder groups. A Disaster Scope (Gad-el-Hak 2008) with five levels (small, medium, large, enormous, and gargantuan disasters), Eshghi and Larson's (2008) categorization with six severity levels (emergency situation, crisis situation, minor disaster, moderate disasters, major disasters, and catastrophe), a Fatality based disaster scale (Wirasinghe et al. 2013a) with seven levels (emergency, disaster type 1 and 2, catastrophe type 1 and 2, calamity, and cataclysm), and a Universal Disaster Severity Classification (Caldera 2017) with ten severity levels (emergency, disaster type 1 and 2, calamity type 1 and 2, catastrophe type 1 and 2, cataclysm type 1 and 2, and partial or full extinction) are available.

The linguistic method is an important piece for communicating disaster severity. These disaster terminologies are even adapted with modification when creating severity scales (for both individual and common classification systems) to emphasize the degree of impact an event has. Although the severity scales mentioned previously are developed using the linguistic method to categorize the different levels of severity, in all but the last two common scales, the proposed labeling appears to be arbitrary, particularly in all individual and common scales. The last two scales did pay some attention when selecting the terminologies to label the levels of severity; however, they did not consider the current view of the people who are going to use these scales. Proposing a clear definition and criteria to terminologies is important, but often, people do not refer to the definition, especially in disaster situations, and they assume the lexical (verbal) meaning of the word. Therefore, it is important to consider the users' perspectives when selecting labels to categorize disaster severity levels.

Therefore, selecting specific terminologies to represent different levels of severity for a global audience is challenging and needs careful consideration because the lexicon (dictionary) meaning and the lexical (verbal) meaning of these terminologies may vary and depend on time, location, individual experience, and situation. In this paper, people's perception about the commonly used terminologies to describe the severity of an event is discussed: common understanding about the disaster terminologies, whether these terminologies have an order of seriousness in people's minds, or whether these terminologies are randomly used, and if there is an order of seriousness for these terminologies, what is that order. It also compares the lexical (verbal) meaning and the lexicon (dictionary) meaning of these terminologies by using respondents' rankings. Additionally, how people state some major events, such as the Corvid-19 pandemic, is also investigated in this paper as a case study. A suitable order of the natural disaster terminologies to label the categories of a global severity classification system is proposed with definitions to build upon a globally accepted consistent method to communicate the severity levels of disasters using a linguistic method. 


\section{Descriptive Terminologies For Natural Disasters}

Emergency, disaster, calamity, catastrophe, cataclysm, or apocalypse are the commonly used English terminologies that describe the nature of an event. Although these terminologies have some order of seriousness, expressing the level of impact is difficult because this primary system has several deficiencies.

One main shortcoming is that the same terminologies are used interchangeably. For example, the Oxford dictionary (Oxford University 2010) describes a disaster as a catastrophe and then defines catastrophes and calamities as disasters. Another example, Merriam-Webster (Merriam-Webster 2013), describes a disaster as a calamity and a calamity as a disaster. Even in the literature on disasters, there is controversy about whether the term 'catastrophe' can be differentiated from 'disaster' or whether they are synonyms (Penuel et al. 2013) because almost all well-known dictionaries use these terminologies synonymously in their definition. Confusion occurs because the definitions of disaster terminologies in ordinary dictionaries are very wide. There is no coherent method to distinguish one term from the other, even in dictionaries for disaster terminologies (Wirasinghe et al., 2013b).

\subsection{Natural Disaster Lexicon (Dictionary) Meaning Change Over Time}

The linguistic method has been applied to classify various magnitudes of natural disasters that adversely affected all living beings since the beginning of civilized society. Therefore, these terminologies progress with time, and their meaning and gravity levels have also gradually changed. For instance, the term disaster was added to the English vocabulary in the late $16^{\text {th }}$ century and meant 'ill-starred event,' which means that the event caused an unfavorable situation or a misfortune to the planet; currently, it is defined in the Oxford Dictionary as 'a sudden accident or a natural catastrophe that causes great damage or loss of life. Etymological dictionary definitions of apocalypse, calamity, cataclysm, catastrophe, disaster, and emergency are given in Table 1. The current definitions of the same terminologies as documented in the Oxford Dictionary of English are given in Table 2. A comparison of Table 1 and Table 2 shows how the meaning of these terminologies has changed dramatically.

Table 1 Etymological definition

Table 2 Current English dictionary definition

The level/order of the seriousness of these terminologies has also changed over time due to the evolution of the meaning. According to the analysis of etymological definitions and current English dictionary definitions, the level/order of the seriousness of the terminologies from lowest to highest according to etymological definitions is emergency, apocalypse, calamity, cataclysm, catastrophe, and disaster; in contrast, the order is emergency, disaster, calamity, cataclysm, catastrophe, and apocalypse according to current English dictionary definitions (Caldera 2017). We can see that the level/order of the seriousness of the disaster terminologies changes significantly, and emergency remains at the same level throughout. The lexicon (dictionary) meaning of these terminologies and their order of seriousness vary depending on the era.

\subsection{Disaster Lexical Change as Per Individual/Situation}

The general population's perspective about these disaster terminologies differs. For example, the term 'disaster' applies to everything from an event like an earthquake to occasions when two people turn up for a party wearing the same clothes. Confusion occurs because people use different terminologies in different ways (Rutherford et al. 1983). Also, there are different meanings to these terminologies depending on their contexts, as they are often used as metaphors and have different connotations (Caldera and Wirasinghe 2015b). For instance, a catastrophe in Geology is a sudden and violent change in the physical order of things, such as a sudden upheaval, depression, or convulsion affecting the Earth's surface and the living beings upon it. Some have supposed that a catastrophe occurs at the end of successive geological periods (Oxford University Press 2014). However, Shakespeare used the term 'catastrophe' to express insult: "I'll tickle your catastrophe" in Henry IV, Part 2 (Shakespeare 1600). Thus, the vocabulary, context, and interpretation of each term are not fixed (Kelman 2008). Therefore, it is difficult to understand the general population's viewpoints about these disaster terminologies, or their confusion, misunderstanding, and misinterpretation about the current definitions. 
A clear sense of the real magnitude of a disaster's severity cannot be comprehended merely by using the linguistic method because of this deficiency. Therefore, the same event is described using several terminologies. One observer's 'disaster' event might be another's 'catastrophic' event, or even 'calamity' event, depending on personal feelings, knowledge, purpose, and experience towards the event. On the other hand, events that have very different levels of severity are frequently put into the same category. For example, both the 1998 Hurricane Mitch (Schenk 1999) and the 2004 Indian Ocean Tsunami (WiscNews 2018) are categorized as catastrophes. However, compared to the Indian Ocean tsunami, Hurricane Mitch's impact was much smaller: it struck eight (8) of the Caribbean and Central American countries and killed 11,000 people, while the Indian Ocean tsunami affected 12 countries of Asia and Africa and killed about 230,000 people. Therefore, expressing the level of impact is difficult using these terminologies.

Thus, meaning and gravity levels of the natural disaster lexicon (dictionary) meaning and lexical (verbal) meaning may vary depending on time, individual experience, and type of situation. Therefore, it is important to investigate whether there is a particular ordering of these terminologies that would be suitable to label the categories of a global severity classification system.

\section{Methodology}

Surveys have been conducted to investigate people's perceptions about natural disaster terminologies and how they use these disaster terminologies. The University of Calgary Conjoint Faculties Research Ethics Board approved these surveys. In this study, the non-probabilistic sampling techniques are used because, in this research, the population considered is the entire population, which is too large to examine, as the study is looking for a ranking suitable to use for a global audience. Thus, due to time and cost considerations, it is impossible to draw random probability sampling that gives each member of the population a known (or equal) chance of participating in the study. Therefore, a combination of a convenience sampling method (recruit participants who are readily available and willing) (Fink 2003a) and a snowball sampling method (recruit participants via other participants) (Fink 2003a) was used to reach respondents. Potential survey participants were invited to take part in the survey using the survey links, and these links were sent/advertised through emails, short message services, social media (e.g., Facebook and LinkedIn), newsletters (e.g., the e-PEG newsletter of the Association of Professional Engineers and Geoscientists of Alberta and electronic newsletter of the World Federation of Engineering Organizations - Committee on Disaster Risk Management), websites, online discussion platforms (e.g., Catastrophe Indices and Quantification Inc., Canadian Risk and. Hazards Network), and by distributing handouts in conferences.

As this study was conducted in English, the target population of this study was English-speaking adults who were 18 years or older, and were internet users that consisted of less than 1 billion people. Nearly 1.35 billion out of 7.8 billion spoke English, with about $26 \%$ of the world being under 15 years of age (Szmigiera 2021). In addition, there were 4.66 billion (59.5\% of the global population) active internet users worldwide (Johnson 2021) as of January 2021 (it was $49 \%$ in the year 2017 (Worldbank 2021)). A web-based international survey was conducted to enable access to large and geographically distributed populations in a cost-effective and fast manner. The web surveys were launched on the Alchemer (previously known as SurveyGizmo) website to reach the global participants.

Since the study was based on ordinal data (ranking/ordering values) (Lehmann 1998; Hayes 2021) and the study was better represented by the median than the mean, non-parametric tests were used. The study was better represented by the median than the mean because the center of a skewed distribution can be better measured by the median, where $50 \%$ are above the median and $50 \%$ are below. For example, consider a scenario where most of the people give a higher ranking to a particular term, but very few give a lower ranking (a few outliers) to that term, then the mathematical mean decreases even though the median does not change. When the distribution is skewed enough, the mean is strongly affected by changes far out in the distribution's tail, whereas the median continues to reflect the center of the distribution more closely (Minitab 2015).

The survey was conducted to find out the people's perspective toward the disaster terminologies. The surveys objective was to determine whether there are differences in ranking the disaster terminologies among people; the research question was, are there any differences in ranking the disaster terminologies among people; and the hypothesis is there are no differences in

Page $5 / 30$ 
ranking the disaster terminologies among people. Therefore, the independent variable in this study was people, and the dependent variable is rankings of the terminologies. The survey type was an international web-based survey as the target population was adult English speakers. There are no subgroups the global population was considered, but if we wanted to find out if there were differences in ranking according to the geographical areas, then those areas considered were the sub-groups (e.g., six (6) or seven (7) continents). Generally, a statistical rule of thumb is that about 30 people are needed in each group (Fink 2003a). However, for the nonparametric tests, the sample size requirement was $1.15 \%$ of the sample size of the parametric test (Lehmann 1998). Thus, about 242 sample sizes were required to represent all continents in non-parametric tests.

The terminologies that describe the magnitude of a natural phenomenon, such as calamity, cataclysm, catastrophe, disaster, and emergency, were considered to investigate whether there was a significant difference in seriousness levels for these five (5) terminologies or whether people considered these terminologies as synonyms and used them randomly. The terminology "Armageddon," which describes "a usually vast decisive conflict or confrontation" or "a terrible war that could destroy the world" (Oxford 2010), was not used because it did not refer to natural events but rather human-caused catastrophes. Similarly, the terminology "apocalypse" was biased towards some religions, that consider the word to be associated with the destruction or end of the world, and hence eliminated from this analysis.

To examine the previous research question, a web-based survey was conducted and all five (5) terminologies (calamity, cataclysm, catastrophe, disaster, and emergency) were presented in alphabetical order to each respondent. Then, the respondents were asked to rank the five (5) terminologies according to the level of seriousness from the lowest (Level 1) to the highest (Level 5) severity. In the two (2) surveys conducted, the respondents were asked to rank the five (5) terminologies. In the first survey, the definitions of the terminologies were not given to the respondents (to see the ranking of lexical (verbal) meaning), while in the second survey, the Oxford dictionary definitions were given to the respondent (to see the ranking of lexicon (dictionary) meaning. In these surveys, the five (5) samples of each terminology are related because respondents could not give the same rank to two (2) different terminologies; therefore, the ranks received for the five (5) terminologies were dependent on each other. The non-parametric tests below (Siegel 1957) were conducted to find solutions to the following hypothesis:

1. Friedmen's test was carried out to determine whether people use these five terminologies randomly or whether there is a significant difference in the rank of each terminologies.

Ho: There is no significant difference between the mean ranks of the disaster terminologies

2. If the ranks were not randomly distributed, then Kendall's W Test was carried out to determine whether there was an agreement between respondents' rankings.

Ho: There was no agreement among the respondents in the ranking of different terminologies $(\mathrm{W}=0)$.

3. If there was an agreement between respondents' ranking, then the Wilcoxon signed-rank test was carried out for each pair of terminologies to determine which terminologies exhibited differences in ranking and which terminologies showed similarities in ranking and discovered peoples' ranking of these natural disaster terminologies. More details about the Wilcoxon signedrank test are available in Appendix 1.

Ho: The median difference $\left(M_{A}-M_{B}\right)$ was equal to zero. Eg: Ho: $M_{\text {Cataclysm }}-M_{\text {Calamity }}=0$

\section{Analysis Of Perception About Natural Disaster Terminologies}

\subsection{According to Lexical (Verbal) Meaning}

The first web survey was launched from September 2015 to December 2020. There were 1170 responses collected during this first survey, to see the rankings of lexical (verbal) meaning, the definitions of the terminologies were not given to the

Page 6/30 
respondents when they were asked to rank the five (5) terminologies. Out of all respondents, 808 gave the rankings to the disaster terminologies, and only 624 respondents (i.e., 53.3\%) fully ranked all five (5) terminologies in the survey. The first three columns of Table 3 (Columns 1 to 3 ) show the number of respondents who ranked each term and those who did not. A considerable number of respondents did not rank 'cataclysm' or 'calamity' compared to the other three terminologies. Most people were familiar with the terminologies 'emergency,' 'disaster,' and 'catastrophe.' Further, the terminologies 'emergency' and 'disaster' were often used in government spheres, and the terminology 'catastrophe' was often used in insurance spheres. The terminologies calamity and cataclysm are typically colloquial; 'calamity' refers more to emotional reactions (Oxford University 2010), and 'cataclysm' refers to flood-related disasters (Cresswell 2009; Oxford University Press 2014; Harper 2001). Some respondents might have avoided ranking the terminologies not because they were unfamiliar with the terminologies but because they found the terminologies to be subjective and may have preferred a more objective differentiation regarding disaster severity.

Table 3 Number of response rankings collected for natural disaster terminologies

For those respondents who completed the ranking, Figure 1 shows the frequency of the ranking of the given terminologies, and it shows that all five terminologies were ranked 1 to 5 . The highest frequent terminologies for lowest rank one (1) (green bars) is 'emergency,' rank two (2) (yellow bars) and rank three (3) (red bars) is 'disaster,' rank four (4) (purple bars) is 'catastrophe,' and rank five (5) (ash bars) is 'cataclysm.' 'Calamity's' highest and second-highest frequencies were for rank three (3) and rank two (2), respectively; and they were lower than the respective frequencies for 'disaster.' The frequency difference between 'disaster' and 'calamity' for rank two (2) (i.e., 42) was higher compared to rank three (3) (i.e., 13). The pre-assumption was made according to the frequency distribution of ranking that emergency, disaster, calamity, catastrophe, and cataclysm might be the perceived level/order of seriousness for the five disaster terminologies. Additionally, median (and interquartile range) perceived order as emergency, disaster, calamity, catastrophe, and cataclysm, and their values are shown in Table 3 (Columns 4 and 5 respectively), which agrees with the pre-assumption. On the other hand, the mean rank would order the level of seriousness of these terminologies from low to high, as emergency, calamity, disaster, catastrophe, and cataclysm and their values are shown in Table 3 Column 6, which swap the ranks of disaster and calamity. Three (3) non-parametric tests were conducted to examine the three (3) hypotheses mentioned previously.

Fig. 1 Respondent ranks for Natural Disaster Terminologies

\subsubsection{Friedman's test}

According to the Friedmen test, for 624 respondents who completed the ranking, there was an overall statistically significant difference in the perceived order of the disaster terminologies depending on rank given to disaster terminologies with, $\chi^{2}(4)=$ 402.397, $p=0.000$.

\subsubsection{Kendall's test}

Kendall's W $=0.161$ indicates that there was some agreement among the 624 respondents in ranking the five (5) terminologies. Since this was a large sample $(n>7)$, there existed a considerable and significant agreement among the respondents when ranking the different terminologies, $\chi 2(4)=402.397, p=0.000$. Thus, it was evident that at least one terminology is ranked significantly higher than the other.

\subsubsection{Wilcoxon test}

Post hoc analysis with Wilcoxon signed-rank tests was conducted with a Bonferroni correction applied, resulting in a significance level set at $p<0.005$ (the significance values were adjusted to compensate for multiple comparisons). Table 4 shows the output of the Wilcoxon signed-rank test on each pair of the combinations. According to the Bonferroni-adjusted significance level, there was a statistically significant difference in perceived ranks in all pairs except the catastrophe cataclysm pair in accordance with the respondents' rank ( $p$-values $<0.005$ ). However, there were no significant differences in perceived ranks between the catastrophe and cataclysm $(Z=-0.492, p-v a l u e=0.623>0.0025)$. The level/order of the 
seriousness of the natural disaster terminologies: emergency, calamity, and disaster have a rank of 1,2, 3 , respectively, and catastrophe and cataclysm had similarly earned the highest rank 4.

Table 4 The test statistics of the Wilcoxon signed-rank test for pairwise samples

\subsubsection{Survey sample characteristics}

Figures 2 to 7 show the demographics of the 624 respondents fully ranked all five (5) terminologies in the survey. Figure 2 shows the distribution of respondent locations. A significant number of respondents are from North America. The secondhighest number of respondents were from Asia. There were a considerable number of respondents from Europe and Oceania, but very few participants were from Africa and South America. Most respondents resided in Australia, Canada, China, Japan, Korea, Singapore, Sri Lanka, the United Kingdom (UK), and the United States of America (USA). More than 75\% of the respondents were from English-speaking countries. Figure 3 shows the education levels of the respondents. Out of the $56 \%$ of respondents who answered the question regarding their education level, $92 \%$ had at least a bachelor's degree (i.e., $52 \%$ of respondents, as shown in Figures 3). Therefore, the sample comprised well-educated respondents. Of this sample, approximately $71 \%$ were male (i.e., $39 \%$ of respondents who answered the question regarding their gender and fully ranked all five terminologies as shown in Figures 4). Figure 5 shows the age distribution of the respondents. The sample was distributed between ages 18 to 74 years; the 25-34 age range was double the representation compared to the other groups. More than $38 \%$ of the respondents had experienced natural disasters (i.e., more than $22 \%$ of respondents who fully ranked all five terminologies, see Figure 6). Similarly, more than $38 \%$ of the respondents had been involved in natural disaster-related work (i.e., more than $22 \%$ of respondents who fully ranked all five terminologies, see Figure 7 ). There was no discernable difference in education, sex, age, and residence between those who completed the ranking process and those who did not. The results of the non-parametric tests are also similar for the full sample (with 1170 or 808 responses).

Fig. 2 Geographical distribution

Fig. 3 Education level distribution

Fig. 4 Gender distribution

Fig. 5 Age distribution

Fig. 6 Disaster experience distribution

Fig. 7 Disaster-related work experience distribution

\subsection{Lexical According to Geographical Area}

This survey was about terminologies in the English language that describe the severity of a natural event. English is often used to communicate across nations, and it is the most spoken language internationally; $20 \%$ of the world speaks English (Lyons 2021). Out of the English speakers, 460 million are from Asia, 350 million are from America, 237 million are from Africa, 212 million are from Europe, over 30 million are from Oceania, and 14 million are from South America and Central America. Although English is the most spoken language in the world, it is the $3^{\text {rd }}$ most native spoken language because the majority are not native English speakers; about only 370 million people speak English as their first language (Lane 2021). Most of the native English speakers are from North America: the USA (297.4 million) and Canada (30 million) (Lyons 2021). The respondents who ranked the disaster terminologies were from all over the world may not have had English as their first language. Therefore, it was interesting to see how people viewed these terminologies in different continents and whether there was a significant difference between English speakers' and native English speakers' (considering North America) and their rankings of the disaster terminologies using the lexical (verbal) meaning.

This study also investigated whether there was a significant difference in native English speakers' perception of natural disasters using the lexical (verbal) meaning. Non-parametric statistical tests were conducted to identify whether there was a

Page $8 / 30$ 
significant difference between respondent rankings according to their geographical area. The Friedmen test and Kendall's W test showed there was an overall statistically significant difference in a perceived order of the disaster terminologies depending on the rank given to disaster terminologies; there was some agreement among the respondents in ranking the five (5) terminologies for Global, North America, Asia, Europe, and Oceania $(p<0.05$ and $n>7)$. Due to insufficient data $(n<7)$, South American and African continents were not considered for the analysis. Table 5 shows the results obtained for pairwise samples together with p-values for respondents who ranked all five (5) terminologies in Global, North America, Asia, Europe, and Oceania.

Table 5 Wilcoxon signed-rank test results for pairwise samples of lexical (verbal) meaning

A Wilcoxon signed-rank test showed that a catastrophe - cataclysm pair does not elicit a statistically significant change in perceived severity order for all samples ( $p<0.005$ where 0.005 is the Bonferroni-adjusted significance level for ten pairs). In addition, all four continents (North American, Asian, European, and Oceania) did not produce a statistically significant change in the perceived severity rate for the calamity - disaster pair as well, although the Global sample did. Moreover, Asian, European, and Oceania samples did not generate a statistically significant change in perceived severity rate for the disaster cataclysm pair, whereas both Global and North American samples did. Further, European and Oceania samples did not generate a statistically significant change in the perceived severity rate for the emergency - calamity pair, and the disaster catastrophe pair, whereas Global, North American, and Asian samples did. Nevertheless, the Oceania sample only generated a statistically significant change in the perceived severity rate for the emergency - disaster pair. According to the previous results of the Friedmen test and Kendall's W test of Oceania respondents, there was an overall statistically significant difference in a perceived order of the disaster terminologies, and there is some agreement among the respondents in ranking the five (5) terminologies; those results were obtained only because of the emergency - disaster pair, as Oceania respondents ranked 'disaster' significantly higher than the 'emergency.' However, to test significance for permutation tests (e.g., that $z$ is normally distributed) requires the sample size to be greater than 60 (Statistics Solutions, 2021); hence European and Oceania continents may not give a proper result due to insufficient data $(n<60)$.

According to the above analysis, overall respondents ranked disaster terminologies to four (4) levels from lowest to highest emergency, calamity, disaster, and catastrophe/cataclysm. While the global respondents had four (4) levels for five (5) disaster terminologies, North American respondents had three (3) levels for the five terminologies: emergency, calamity/disaster, and catastrophe/cataclysm (see Table 6). Similarly, Asian respondents had three (3) levels, like North American respondents except for the disaster - cataclysm pair, which complicated the rank that each disaster term obtained. European respondents had two (2) levels for five (5) terminologies: emergency/calamity and disaster/catastrophe/cataclysm; however, the disaster - calamity pair complicated the rank that each disaster term obtained. On the other hand, Oceania respondents had one (1) level for all five (5) terminologies: emergency/calamity/disaster/catastrophe/cataclysm; however, the results of the pair: emergency - disaster complicated the rank that each disaster term obtained. The results of all three (3) nonparametric tests were also similar for the full sample (with 1170 or 808 responses).

Table 6 The level of seriousness of the five (5) terminologies according to different sample

Emergency received the lowest rank, and all the other terminologies were higher ranked than 'emergency' for Asians, North Americans, and global respondents. Both catastrophe and cataclysm obtained the highest rank from North Americans and global respondents. Although the calamity and disaster pair obtained two (2) ranks from global respondents (i.e., Rank 2 and Rank 3 respectively), these two (2) terminologies were ranked similarly in the middle rank by North Americans. Thus, there is a slight variation in perception about the order of the seriousness of the disaster terminologies in English speakers and native English speakers (according to their geographical locations).

\subsection{Lexical (Verbal) Meaning vs. Lexicon (Dictionary) Meaning}

To see whether there was a significant difference in perceptions about the order of the seriousness of the disaster terminologies between the lexical (verbal) meaning and the lexicon (dictionary) meaning, a similar survey was conducted for 
the second time. In this survey, all five (5) terminologies were presented to each respondent in alphabetical order with their Oxford dictionary definitions (shown in Table 2), and they were asked to rank the five (5) terminologies according to the level of seriousness from the lowest (Level 1) to the highest (Level 5) in order of the seriousness of the terminologies. Then, the same analysis was conducted to see whether the general understanding of the terminologies using the lexical (verbal) meaning would differ with the presence of the lexicon (dictionary) definitions. The responses were collected from September 2020 to July 2021 in the second web survey. There were 847 responses collected during that period, and out of all respondents', 522 gave rankings to the disaster terminologies, and only 443 respondents (i.e., $52.3 \%$ ) fully ranked all five (5) terminologies in the survey. This response percentage was closer to the first survey, which was $53.3 \%$.

\subsubsection{Survey sample characteristics}

Out of the 443 respondents that fully ranked all five (5) terminologies in the survey, a significant number of respondents were from Asia and North America. There were a considerable number of respondents from Europe, Oceania, and Africa, but none of the respondents were from South America. Most respondents resided in Australia, Canada, China, India, Japan, Nigeria, Portugal, Serbia, Singapore, Spain, Sri Lanka, the UK, and the USA. More than 47\% of the respondents were from Englishspeaking countries. Out of the $69 \%$ of respondents who answered the question regarding their education level, $90 \%$ had at least a bachelor's degree (i.e., $60 \%$ of the 443 respondents). Therefore, the second sample also comprised well-educated respondents. Of this sample, approximately $49 \%$ were male (i.e., $32 \%$ of the 443 respondents who answered the question regarding their gender). This sample was also distributed between ages 18 to 74 years; the 35-44 age range had double the representation compared to the other age groups. Out of the $72 \%$ of respondents who answered the question regarding the disaster experience, more than $56 \%$ of the respondents had experienced natural disasters (i.e., more than $40 \%$ of the 443 respondents). Similarly, out of the $73 \%$ of respondents who answered the question regarding disaster involvement, more than $45 \%$ of the respondents had been involved in natural disaster-related work (i.e., more than $33 \%$ of the 443 respondents). There was no discernable difference in education, sex, age, and residence between those who completed the ranking process and those who did not. The results of the non-parametric tests were also similar for the full sample (with 847 or 522 responses).

\subsubsection{Differences in verbal and dictionary meaning globally and according to the geographical area}

Table 7 shows the comparison between mean ranks and their order for the five (5) terminologies with definitions (second survey) and without definitions (first survey) for Global, North American, Asian, European, and Oceania samples. When participants were provided with the dictionary definitions (lexicon meaning), the mean rank of the five (5) terminologies in order of seriousness from low to high was emergency, calamity, disaster, catastrophe, and cataclysm for Global, North American, Asian, and European participants. However, participants from Oceania showed equal mean rank for emergency and calamity and swapped the ranks of disaster and catastrophe (Table 7 Columns 7 to 11). Similarly, when participants were not provided the definitions and had to rely on the lexical (verbal) meaning, the mean rank of the five (5) terminologies in order of seriousness from low to high was emergency, calamity, disaster, catastrophe, and cataclysm for Global, North American, and European, however, the ranks of catastrophe, and cataclysm were switched for Asia and Oceania (Table 7 Columns 2 to 6 ).

Table 7 The Mean Rank of the samples

The results of the non-parametric statistical tests conducted to identify whether there was a significant difference between respondent rankings according to the global samples and their geographical area with or without definitions are shown in Table 8. According to the Friedmen tests, there was an overall statistically significant difference in the perceived order of the disaster terminologies depending on the rank given to disaster terminologies as $p<0.000$ for all samples except Oceania with definition as P-value $=0.215$. So, with the presence of the dictionary meanings, Oceania respondents randomly rank the five (5) terminologies thus the continuation of the other two (2) tests was not necessary for the Oceania sample; however, the result is shown for consistency. Similarly, Kendall's W tests indicated that there was some agreement among the respondents in ranking the five (5) terminologies as $p<0.000$ for all samples except Oceania with definitions as $P$-value $=0.215$. Thus, the Friedmen tests and Kendall's W tests showed there existed a considerable significant agreement among the respondents when 
ranking the different terminologies, and it was evident that at least one term was ranked significantly higher than the other except for Oceania with definitions as all samples had $n>7$.

Table 8 The test statistics of the Friedman test and Kendall's W Test

Table 9 shows the results of the Wilcoxon signed-rank test on each pair of the combinations for respondents who ranked all five (5) terminologies in Global, North America, Asia, Europe, and Oceania with definitions. Due to insufficient data, South American and African continents were not considered for the analysis. The results showed that emergency - calamity, disaster - catastrophe, disaster - cataclysm, and catastrophe - cataclysm pairs did not elicit a statistically significant difference in perceived severity order for all samples ( $p<0.005$, where 0.005 is the Bonferroni-adjusted significance level for ten pairs). In addition, all four (4) continents (North American, Asian, European, and Oceania) did not produce a statistically significant change in the perceived severity rate for the calamity - disaster pair as well, although the Global sample did. Moreover, the Asian continent generated a statistically significant change only in the perceived severity rate for the calamity - cataclysm, and the calamity - catastrophe pairs. Furthermore, none of the pairs in the Oceania continent generated a statistically significant change in perceived severity rate, which agreed with the results of the Friedmen test and Kendall's W test results.

Table 9 The results of the Wilcoxon signed-rank test for pairwise samples with definitions

According to the above analysis, with the presence of definitions for the terminologies, overall respondents ranked disaster terminologies to two (2) levels: emergency and calamity as the lowest level and disaster, catastrophe, and cataclysm as the highest level. Similarly, North American and European respondents had the same two (2) levels for the five (5) terminologies, except for the disaster - calamity pair, which complicate the rank that each disaster terminology obtained for both North American and European continents. On the other hand, Asian continent respondents did not differentiate the terminologies with more than one (1) level except for the calamity - cataclysm and calamity - catastrophe pairs, which complicated the rank that each disaster terminology obtained. Oceania respondents randomly ranked the terminologies as they were not differentiating the terminologies according to their definitions. The given definitions (Oxford dictionary definitions) did not differentiate the disaster terminologies more than two (2) levels for a global audience.

Table 10 shows the comparison between respondents' rank of the disaster terminologies with and without the presence of the terminology's definitions. For the global sample, without the terminology's definitions (i.e., lexical (verbal) meaning), there was a clear differentiation between rank for emergency, calamity, disaster, and catastrophe/cataclysm, which had four (4) different levels. However, when the definitions of the terminologies were present (i.e., lexicon (dictionary) meaning), respondents did not differentiated terminologies with more than two (2) levels: emergency/calamity and disaster/catastrophe/cataclysm. Similarly, for North Americans, without the terminology's definitions, there was a clear differentiation among ranks with three (3) different levels: emergency, calamity/disaster, and catastrophe/cataclysm; however, with the presence of definitions, they did not differentiated terminologies with more than two (2) levels. In addition, Asians who had three (3) different levels without the presence of the disaster terminology's definitions only had one (1) level with the presence of the definitions. European and Oceania respondents had the same rankings with or without the definitions. However, the European and Oceania continents may not have given a proper result due to insufficient data $(n<60)$ for the Wilcoxon signed-rank test. Therefore, there is a clear differentiation between respondent rankings for the lexicon (dictionary) meaning and the lexical (verbal) meaning for Global, North American, and Asian respondents.

Table 10 The level of seriousness of the five (5) terminologies according to different sample

There is a significant difference in perceptions about the order of the seriousness of the disaster terminologies between the lexical (verbal) meaning and the lexicon (dictionary) meaning. The given disaster definitions (Oxford dictionary definitions) do not differentiate between the disaster terminologies. Therefore, if these terminologies are used to differentiate the severity levels of a standard classification system, a clear definition to differentiate each disaster terminology from one another is necessary. 


\section{Perceptions About Covid-19 Pandemic}

As discussed previously, the gravity levels of descriptive terminologies changes over time, individual opinions, and varying situations. The recent coronavirus (2019-nCoV) pandemic (Covid-19) has made a huge impact on humans making it a good example of a major event. Covid-19 first appeared in Wuhan, China, in December 2019; this outbreak rapidly escalated from endemic to epidemic within a few days and from epidemic to pandemic within a few months (Centers 2020); the World Health Organization (WHO) announced that the outbreak of Covid-19 was a global pandemic on 12 March 2020 (World 2020). As of 24 January 2022, there have been more than 353.8 million confirmed cases, more than 5.6 million fatalities reported globally (Johns 2022). Numerous new cases are reported daily around the world. Therefore, to see how people perceive major events, we investigate peoples' perceptions of the Covid-19 pandemic as a case study.

During the second survey, the respondents were also asked to select which single terminology out of the given five (5) terminologies they would use to describe the ongoing Covid-19 pandemic. The real-time statistics of Covid-19 (global confirmed cases, global deaths, and global recovered cases) were also presented to the respondents during this question. Out of the 848 respondents, 674 (i.e.,79.5\% of the respondents) selected one of the five (5) terminologies provided by the researchers to describe the severity of Covid-19. The frequency percentage distribution of the answers is shown in Figure 8. Out of the 674 respondents, $35.5 \%$ described Covid- 19 as a disaster, $25.4 \%$ as a catastrophe, $23.3 \%$ as an emergency.

Fig. 8 Frequency distribution of people's perception about the ongoing Covid-19 pandemic

This survey was conducted during the Covid-19 pandemic from September 2020 to June 2021; with increments of Covid-19 severity, the respondents' choices may have changed as these terminologies depicted an increasing level of seriousness. To capture any randomness and/or time series trend in the data, the frequency percentage of respondents' choice for each month was drawn; this time series trend for each terminology is shown in Figure 9. Although the data seemed to show a random pattern in 2020, during the first half of 2021, there was an increment of respondents who chose to describe the Covid-19 pandemic as a disaster or catastrophe, while there was a reduction in respondents' choosing the terminologies; calamity, cataclysm, and emergency.

Fig. 9 Change in perception about the ongoing Covid-19 pandemic

The respondents' perceptions may have changed due to the increment of Covid-19 impacts with the emerging presence of variants of concern (VOC). According to Figure 9, for each terminology, there is a random pattern (September 2020 to January 2021), then there is a steady-state (January to April 2021), and finally there is an increasing/decreasing trend (April to June 2021). Table 11 shows the Covid-19 impacts during this period, and according to designated VOC in WHO (2022), Alpha and Beta variants were designated on 18 December 2020, Gamma (also known as P1) variant was designated on 11 January 2021, Delta variant was designated on 04 April 2021, and Omicron variant was designated on 24 November 2021; thus, these variants and their impacts have also played a major role during the pandemic and have influenced changes in people's perceptions.

\section{Table 11 Covid-19 statistics}

According to Figure 9, people prevented randomly assigning the terminologies to Covid-19 at the end of December 2020, at the same time VOC was designated. After January 2021 (when the Gamma variant was designated and the total confirmed cases for Covid-19 exceeded 100 million with more than two (2) million fatalities), respondents offered a steady flow of labels for the Covid-19 pandemic. For example, most of them recognized it as a disaster, some recognized it as a catastrophe or emergency, and some saw it as a calamity or a cataclysm. After April 2021 (when the Delta variant was designated and the total confirmed cases exceeded 150 million with more than three (3) million fatalities), people's tendency to recognize the Covid-19 pandemic as a disaster or catastrophe increased gradually, while their tendency to recognize Covid-19 as an emergency or calamity or cataclysm decreased. At the end of June 2021 (i.e., the end date of the survey), 50\% of the respondents described the Covid-19 pandemic as a disaster, $33.3 \%$ as a catastrophe, and the rest as an emergency. None of the respondents described Covid-19 as a calamity or cataclysm. The frequency of respondents who described Covid-19 as a calamity or cataclysm was low

Page 12/30 
throughout the survey, compared to disaster, catastrophe, and emergency. This case study clearly showed how people referred to some major events and how their perceptions changed with the situation.

\section{Proposed Qualitative Universal Disaster Severity Classification}

Integrating descriptive terminologies used by an emergency management system improves mutual understanding and is easier to manage with minimal confusion. For instance, the terminologies emergency, disaster, and catastrophe have different levels of seriousness, where seriousness increases from emergency to disaster to catastrophe, as shown in Table 6 (Columns 1 to 5) and Table 7 (Columns 1 to 11). Therefore, these terminologies should be used instead of the headings that merely state type 1, 2, 3. For example, disaster managers and emergency responders use incident management teams (IMTs) - typing (United 2020; Alberta 2020). IMTs are typed from Type 1 to Type 5 according to the complexity of incidents they can manage and are part of an incident command system. A Type 5 IMT can manage a small community fire; however, to manage a major flood disaster managers may require a Type 4 or lower IMT. Confusion can arise about whether Type 1 or Type 5 is the most critical. Hence, a universal linguistic method that integrates the existing systems is essential. Furthermore, selecting the appropriate terminologies for different severity levels should be conducted with careful evaluation.

\subsection{Proposed Order of Natural Disaster Terminologies for Global Audience}

The order of the seriousness of the current dictionary definitions, etymological definitions, and people's perceptions of natural disaster terminologies are shown in Table 12 and are considered to propose the order of seriousness for the considered terminologies for global audiences. When proposing the order, more weight was given to the order of the lexical (verbal) meaning (Column 4 Table 12) compared to the lexicon (dictionary) meaning (Column 5 Table 12) of the people's perception because the proposed order of seriousness is for the current global audience and people often get the lexical (verbal) meaning of the terminology without referring to the given lexicon (dictionary) meaning. Thus, emergency, calamity, and disaster are proposed for Levels 1, 2, and 3, respectively. However, catastrophe and cataclysm had the same level according to the people's perception of the lexical (verbal) meaning and lexicon (dictionary) meaning. Thus, considering the overall order of the mean ranks obtained for catastrophe and cataclysm according to respondent's ranking (Table 7), catastrophe and cataclysm are proposed for Level 4 and 5, respectively. Therefore, according to the previous lexical (verbal) meaning and lexicon (dictionary) meaning analysis, the proposed order of the seriousness of the five (5) terminologies from lowest to highest are emergency, calamity, disaster, catastrophe, and cataclysm. This order is not an arbitrary selection but is supported by the data and considers the current view of people all over the world. Hence, this order is suitable for a global audience, and these labels are suitable categories of a global severity classification system.

Table 12 Natural disaster terminologies and their change in perception

As mentioned previously, the term 'apocalypse' is not considered because this term has religious connotations for some people when discussing the natural disaster terminologies. It could be religiously biased, even though 'apocalypse' refers to the destruction or end of the world. Thus, 'apocalypse' is not a suitable term to represent a severity level for the global audience.

\subsection{Proposed Qualitative Global Severity Classification System}

To build upon a globally accepted communication method to convey the level of severity of disasters using a linguistic method, the above-proposed order of disaster terminologies was applied to the Qualitative Universal Disaster Severity Classification (QUDSC) proposed by Caldera and Wirasinghe (2021) with some modifications. The QUDSC was selected for this purpose mainly for the following five (5) reasons. First, the QUDSC has a reasonable and standard number of levels to articulate the full range of disaster severity. Determining the number of levels for all disasters and all fields (e.g., medical field, rescue field, etc.) was not feasible because the number of required levels can differ depending on the application or context. However, the confusion can be minimized when there is an adequate number of levels to distinguish between different categories of seriousness and when a consistent or standard number of levels exists. Nevertheless, a 0-10 level system of the QUDSC/Universal Disaster Severity Classification Scheme (UDSCS) represents large ranges from almost all socio-economic

Page $13 / 30$ 
factors that directly relate to the severity of an event (Caldera and Wirasinghe 2021). These factors can be further divided to human factors and damage factors and can be expressed within 11 levels using the log scale. The 11 levels of human factors $(\mathrm{H})$, which range from 0 to 7.762 billion people (the world's population in 2020, World 2022a), are shown in Column 2 (Table 13). The 11 levels of damage factors (D), which can range from 0 to United States Dollar (USD) 87.555 trillion (the maximum gross domestic product in 2019, World 2022b), are shown in Column 3 (Table 13). Second, the QUDSC clearly defines the levels of the disaster continuum by (1) re-defining the existing terminologies without using one terminology to define another, (2) outlining the circumstance and impact: damage, injuries, and fatalities, and (3) using better descriptive words to reflect the order of the seriousness of a disaster. Unlike the existing dictionary definitions, these definitions provide a consistent method of differentiating one term from the other as these definitions clearly articulate the real magnitude of different severity levels. Third, the QUDSC is also linked to quantitative techniques that give clear boundaries and guidelines. Fourth, combining these terminologies with the colour-coding scheme in the QUDSC enables easy adaption to any language, country, or culture. The colour-coding system is helpful to some people working or involved in disaster recovery who are not literate or cannot understand the local language or dialect (if working in foreign regions). Therefore, the definitions and colours together ensure broader communication between people and organizations. Fifth, the QUDSC explains the disaster continuum: the impact of a broad range of natural disasters that occur anywhere in the world at any time can be described, measured, compared, assessed, and ranked both quantitatively and qualitatively for all stakeholders to measure the severity of all types of disasters.

Table 13 Ranges of human and damage factors in 0-10 levels

Table 14 shows the proposed Advanced Qualitative Universal Disaster Severity Classification (AQUDSC) for all types of natural disasters for all stakeholder groups with the following five (5) modifications to the QUDSC. First, the order of the seriousness of the terminologies from lowest to highest is as follows: emergency, calamity, disaster, catastrophe, cataclysm, and partial or full extinction. The terminologies Calamity and Disaster's order of seriousness were swapped with one another to address the general understanding of the global audience. As mentioned previously, when disaster strikes, whether clear definitions are given there is no time to refer to them; at these times, people often default to the lexical (verbal) meaning of the term. Thus, the proposed order of seriousness from the lexical (verbal) meaning and lexicon (dictionary) meaning analysis was considered when proposing the AQUDSC. Second, to complete the 0-10 level system that represents the full range of the disaster continuum, with name and definition attached to every level, the UDSCS 0, also labeled as emergency, specifically emergency Level 1, is added with its definition. Emergency representing two levels of the UDSCS, all five (5) terminologies, emergency, calamity, disaster, catastrophe, and cataclysm, considered in the analysis represents two levels of the UDSCS scale, consistently. Third, Type 1 and Type 2 of the terminologies of disaster, calamity, catastrophe, and cataclysm were replaced by the Level 1 and Level 2, and were added to the terminology of emergency as well to differentiate the two (2) levels of emergency. This change was a necessary improvement to the QUDSC because using a terminology, such as 'Level' that gives the meaning of the intended hierarchy, instead of the terminology that will not, such as 'Type.' This will improve the understanding between stakeholder groups at all levels and avoid confusion about whether Type 1 or Type 2 is the most critical. Naming the different categories and using plain language (either by using a term or using a term with its sub-level) to describe the magnitude of a disaster allows for easier management at all levels. Fourth, the definition of the term 'emergency' is changed from "A sudden natural event that causes damage, injuries, and some fatalities" to "A sudden natural event that causes substantial damage, injuries, and some/no fatalities" to also address the disasters with no fatalities but with significantly heavy damage to the community, such as the 2016 Fort McMurray fire. By executing this change, disasters, such as a wildfire in an uninhabited forest that affect only a geographic area and do not have any direct and immediate impact on humans but have long-term adverse effects on the local and global ecosystems, can also be represented in this scale. Realworld examples include the 2016 Fort McMurray fire, which had no fatalities (UDSCS 0 - Emergency Level 1), and the 2013 Alberta flood, which had four fatalities (UDSCS 1 - Emergency Level 2), but both disasters were the costliest Canadian disasters in history. Consequently, neither event is properly represented using the QUDSC scale, but they will be represented in the proposed AQUDSC scale because this advanced quantitative scale combines all impact factors, such as fatalities, injuries, and damages, that addresses the full range of a disaster impact properly. Fifth, the colour for UDSCS 0 changed from 'white' to 'light blue,' and the colours for UDSCS 2 and UDSCS 3 are swapped. By doing this colour change, each term has its colour (an 
emergency is blue, calamity is now green, disaster is now yellow, catastrophe is red, cataclysm is purple and partial or full extinction is black), and all Level 1 terminologies are light colours and all Level 2 terminologies are dark colours. Having consistency is important as it makes it easier to remember for its general audience.

Table 14. Advanced Qualitative Universal Disaster Severity Classification

The QUDSC was combined with the initial quantitative classification - fatality-based to create the Initial Universal Disaster Severity Classification (IUDSC) (Caldera and Wirasinghe 2021); as a result of the above changes made to QUDSC, the IUDSC was also modified according to AQUDSC. The Modified Universal Disaster Severity Classification Scheme (MUDSCS) is shown in Table 15. With the previously mentioned modifications, AQUDSC/MUDSCS have the following improvements compared to QUDSC/IUDSC:

- The purpose of ranking disaster terminologies with AQUDSC/MUDSCS is suitable to use for a global audience because the levels consider the general understanding lexical (verbal) meaning of the users.

- The QUDSC/MUDSCS represents the complete range of severity with labels and clear definitions for each severity level and includes disasters that have no direct fatalities but create significant damages to the community, such as the 2016 Fort McMurray fire.

- A clear labeling system to differentiate each level without confusing which levels are more critical than the other; a consistent colour-coded system that ensures broader communication between the public and emergency and media organizations which enables easy adaption for any language, country, or culture.

Thus, the AQUDSC/MUDSCS will differentiate the disaster severity levels more clearly for the global audience and give a clear understanding of the severity in the disaster continuum.

Table 15 Modified Universal Disaster Severity Classification - Fatality based

\section{Discussion}

On most days, more than one natural disaster occurs somewhere in the world, causing immense hardship to living beings and major property damage and losses. Although these disasters come in all shapes and sizes, ranging from a lightning strike to a super volcanic eruption, their impacts on humans and habitats are similar. The MUDSCS shown in Table 15 is proposed to describe, categorize, compare, rate, and rank the total impact of these events and understand the full scope of their severity.

This classification is used for post-events. The classification of the severity of an event may change as reports on impacts are updated (e.g., the classification for Covid-19 changed with its severity, as shown in Section 5 in Figure 9). Therefore, the degree of severity changes with time and with updated reporting on the disaster. For example, a tsunami, which occurs minutes after earthquakes, volcanic eruptions, landslides, etc., could be categorized as a 'calamity' in terminologies of severity within the first few hours depending on the reported impacts and causalities. However, the impact and causalities can increase days or weeks after the event. Accordingly, the severity of the tsunami could be reclassified as a 'disaster' a day or two after the event, and it could potentially be considered a 'catastrophe' within weeks. Although the accuracy of the severity can change with frequent updates of the impact, it is vital to estimate the severity, even shortly after the event strikes, to provide information to emergency responders and for public reporting and planning. For example, the size of a first-responder contingency depends on the magnitude of the disaster impact. Therefore, predicting the severity with a certain degree of accuracy can accelerate the recovery process. For instance, first evaluations are used for planning, such as whether to call a state of emergency, request international assistance, or involve military forces. Other planning decisions include the following: the resources, such as food, water, medicine, and clothes, that should be stored and delivered to the stricken area; the temporary infirmaries that should be assembled and the scope of such infirmaries; and the number and duration of temporary housing to be fabricated. Proper impact estimation helps to predict the amount of the appropriate allocation of resources and expedite mitigation processes (Löw et al., 2010). Inconsistent identifications of a disaster can result in either overcompensation or undercompensating of their allocation of resources for mitigation. Overcompensation could result in a large waste of resources, while under-

Page $15 / 30$ 
compensation could increase the severity of the impact of a disaster. Additionally, the lessons learned from historical disasters provide helpful information about improving communication with emergency services, disaster relief organizations, media and the general public. A severity scaling system that can measure the impact of any natural event will also be a useful guide for the development and evaluation of national and international disaster planning, mitigation, and hazard reduction efforts (Eshghi et al., 2008). The MUDSCS system clearly describes the scope of a disaster as well as the total impact of a disaster which is intended to provide information to emergency services, disaster relief organizations, media and the general public so that the public reporting, education, and planning over the life of a disaster can be as accurate as possible.

The main advantage of MUDSCS is that it is a single common measurement for all types of natural disasters. When an area is prone to two (2) or more disasters (e.g., floods, tornadoes, landslides, etc.), disaster management centers (DMCs) must assess the appropriate combinations of disasters (e.g., thunderstorms and tornadoes, or snowstorms, floods, and hailstorms, or volcanic eruptions and landslides) and decide which combinations are specific to the area being assessed (Caldera et al. 2016b). They must then rank the most likely individual disaster or combination of disasters that could occur in that area (Wickramaratne et al., 2012). For instance, the Calgary Emergency Management Agency releases a list of top 10 hazards and risks in Calgary (Wood 2016). After ranking the hazards, DMCs must assess the potential impacts of each likely individual or combination event and take actions (or make decisions) based on the potential combined impacts. These impact assessments, with their criticality over other combinations in the list, allow DMCs to allocate the required resources with some justifiable basis appropriately. Thus, impact assessments are simplified by MUDSCS because it is a common classification for all types of disasters that are more informative and consistent than using the variety of unrelated scales for specific disasters.

In addition, warning indications during an event should be given in plain language so that the general public can understand the seriousness of a coming disaster and the urgency of evacuation when required. In warning communications, the intensity of a disaster is commonly used as the measure of the destructive power because the intensity/magnitude is assumed to be the most meaningful to the public. However, intensity and magnitude levels are not the best way to describe the severity level of a disaster because they are only an indication of the strength (i.e., hazard potential) but not the impact (i.e., the vulnerability of a region). The impact depends on where a disaster occurs: it can be quite different in a populated city compared to a rural area. For example, a strong tornado may not be a significant disaster when it touches down in a remote area and has no exposure to humans or property. The highest intensity and magnitude event may not necessarily be the most disastrous. Specifically, a considerable body of research presents data that indicate people often underestimate or ignore warnings for natural disasters and other low probability events (Camerer and Kunreuther 1989; Meyer 2006). Severe natural disasters are low probability, high consequence events. The MUDSCS system uses plain language to categorize disasters; therefore, the MUDSCS can be used to communicate the warnings issued by emergency management systems to the general public so that there is a mutual understanding between both parties.

Moreover, populations are most sensitive to disasters that have high human impacts. Therefore, the MUDSCS system should be used for preparedness and mitigation methods; warnings, evacuation, public awareness, disaster education, and disaster drills. These can help change public opinion regarding the impact of disasters by gaining the public's attention and increased trust in the techniques used by emergency management systems and emergency responders. Thus, response time to warnings can be decreased, and response rates can be increased if the proposed terminologies are used. Consequently, public awareness, education level, and response rate to warnings can be increased using the MUDSCS because a direct relationship between a disaster and human impact is made explicit. As Durage et al. (2014) indicated, "The frequent occurrence and high intensity of natural disasters can impose irreversible negative effects on people. Taking mitigation actions well in advance can avoid or significantly reduce the impacts of disasters." Although it is difficult to avoid property damage due to the sudden onset of a natural disaster, when proper classifications and terminology are used in an emergency management system, fatalities and injuries could be minimized by taking appropriate actions, (such as issuing warnings on time and raising public awareness) (Caldera et al. 2018). Warnings indicating the severity of a natural disaster can be communicated using the clearly defined terminologies of the MUDSCS. This meaningful communication regarding life-threatening situations is more likely to elicit an appropriate public response and may increase public awareness. In addition, confusion can be reduced, mutual 
understanding between the general public and emergency responders can be improved, and decision capabilities can also be improved. These recommended improvements in communication need to be tested before implementation.

The most important advantage of the MUDSCS is that it provides a consistent method for all stakeholders to categorize the severity of all types of disasters. The MUDSCS has a reasonable and standard number of levels to articulate the full range of disaster severity. It also has a clear order of seriousness for the severity levels and clear labeling with definitions to convey the severity levels or the severity potential of a disaster. The increasing level of seriousness from 0 to 10 is defined using qualitative boundaries (outlining the impact factors, damage, injuries, and fatalities) and clearly defined descriptive terminologies. Because of this confusion as to whether UDSCS 1 or UDSCS 10 is the most critical can be avoided. Because the MUDSCS has a reasonable number of levels, events that have different levels of severity will not be in the same category. Therefore, because this MUDSCS system conveys the size of the impact of a disaster, it avoids confusion and improves mutual understanding among stakeholder groups.

Furthermore, during a disaster, when emergency responders communicate with other stakeholders, such as national/regional/local governments, relief agencies, non-governmental organizations (NGOs), and the media, they have no standard classification system that provides a unified understanding of the level of severity of the event. Consequently, officials who are trying to understand the full impact of a disaster do not have a consistent scale that can provide a clear understanding of the potential hazard. So, they cannot alert other stakeholders about the degree of severity. Inconsistent and disconnected severity measures mean that neither members of the general public clearly understand the degree of the emergency nor do the members of emergency management systems clearly understand the potential hazard. The proposed MUDSCS system provides a clear perception of the degree of an event for all stakeholder groups. Thus, this system is expected to avoid inconsistencies and to improve mutual communication among stakeholder groups.

Another advantage of this MUDSCS is it is developed to assess the impact of any uncontrollable forces of nature regardless of disaster type, place, or time. A nation's ability to prepare and manage disasters is more effective when there is a mutual understanding between countries and different emergency management systems at all levels: international, continental, regional, national, provincial, and local. The ability of governments to manage extreme events can be dependent on the system that they use. Currently, countries use different systems to manage extreme events. Because of this either a universal understanding of the systems used by other countries or a global standard is required to prepare better and manage global disasters that affect more than one country. For instance, if there had been a universal system in 2004 when the Indian Ocean tsunami struck 12 countries in Asia and Africa, it may have saved thousands of lives. Thus, MUDSCS is expected to gauge the need for regional, national, and international assistance.

\section{Conclusion}

The Advanced Qualitative Universal Disaster Severity Classification (AQUDSC) is developed to communicate the severity of an event caused by different types of natural disasters in different countries and in different time periods. The AQUDSC/MUDSCS is expected to allow for easier communication and management at all levels by selecting the appropriate terminologies (for the levels and the categories) using plain language to describe the magnitude of a disaster which considers the general public's perception of the disaster terminology. Moreover, combining these terminologies with clear definitions that gives clear boundaries and guidelines to enable easy adaption to any language, country, or culture.

The main advantage of the AQUDSC/MUDSCS is that it will provide a common platform to compare natural disasters. Using this AQUDSC/MUDSCS system, the impact of a broad range of natural disasters that occur anywhere in the world at any time can be described, measured, compared, assessed, and ranked qualitatively. It uses disaster terminologies to describe disasters and uses severity levels and clear definitions with impact factor boundaries to assess disasters using the rating scale 0-10 to rank disasters. In addition, this AQUDSC/MUDSCS system is not confined to disasters resulting from the rapid onset, relatively clearly defined events such as earthquakes, tsunamis, and tornadoes. Disasters resulting from events that are more diffuse in space and time are also incorporated, such as droughts, famine, pollution, and epidemics. Conditions that become disastrous but with less clear start and endpoints are also incorporated because the AQUDSC/MUDSCS also considers slow-moving

Page $17 / 30$ 
disasters. Moreover, it incorporates conditions that become extinction events or massive phenomena, such as super volcanoes or a meteoroid impact. Analyzing the risks and responses to events that have the potential to cause the full or partial extinction of the human race is crucial but curtailed as there are no historical records, but there are geographical records. Therefore, comparisons across regions and time for any type of natural disaster are feasible using this AQUDSC/MUDSCS system.

Most importantly, the AQUDSC/MUDSCS is a single common categorization for all stakeholder groups, such as civilians, emergency responders, disaster managers, relief agencies, all levels of government, NGOs, reporters, media, academics, researchers, and policymakers. This method will provide an overall picture of the severity of natural disasters, help one to understand and educate the public regarding the disaster continuum, and assess a disaster for various purposes. By having an overall picture of the severity of disasters, emergency response management organizations can rapidly estimate the potential impact of a natural disaster, and then, they can quickly respond by properly allocating the appropriate resources, expediting mitigation, and accelerating the recovery processes. Additionally, no matter the type of disaster, similar resources are managed by personnel who allocate available emergency vehicles, essential resources, temporary hospitals, temporary housing, etc. Mitigation efforts are dependent on the estimated disaster impact. Identifying the disaster impact properly and promptly is crucial because lives depend on these decisions. Additionally, a nation's ability to prepare and manage extreme global disasters that affect more than one country will improve if there is mutual understanding among different countries' emergency management systems at all levels. Therefore, MUDSCS is expected to create a universal standard severity classification system to clearly understand the degree of an event and the potential impacts It will avoid inconsistencies, and most importantly, will generate a common communication platform to describe the impact of disasters, ensuring mutual understanding across the globe.

\section{Future Extensions}

This is an ongoing research project to develop an advanced multidimensional UDSCS to understand the disaster continuum both qualitatively and quantitatively. The scope of this paper is to introduce an advanced qualitative universal disaster severity classification that can be used for the global audience to compare the impact of any type of natural disaster. When developing quantitative measures, the initial UDSCS is developed only considering one impact factor, fatalities. However, using the initial scale with one factor does not capture all aspects of an impact of a disaster. An advanced multidimensional quantitative scale that combines all impact factors using a disutility function is also needed to be developed.

\section{Declarations}

\section{Funding}

This work was funded by the Natural Sciences and Engineering Research Council of Canada, Alberta Innovates - Technology Futures, Alberta Motor Association, University of Calgary, and Schulich School of Engineering. This work was also funded in

part by the Catastrophe Indices and Quantification Incorporated's Student Delegate Award 2018 and the Canadian Risk Hazard Network's Larry Pearce Education Award 2015.

\section{Conflicts of interest}

The authors have no conflicts of interest to declare that are relevant to the content of this article.

\section{Availability of data and material}

The data that supports the findings of this research were collected through an international web-based survey, and this study has been approved by the University of Calgary Conjoint Faculties Research Ethics Board (CFREB). The CFREB is constituted and operates in compliance with the Tri-Council Policy Statement: Ethical Conduct for Research Involving Humans (TCPS 2). The respondents' consents were given for presentations and publications of results in a summarized format.

\section{Code availability}

Page 18/30 
Not applicable.

\section{ACKNOWLEDGEMENTS}

The authors would like to thank Professor Emeritus R. B. Bond for his guidance, input, and comments on the disaster terminology section of this paper. The authors also thank all the respondents who participated in the survey and those who helped distribute the survey worldwide.

\section{References}

1. Alberta Emergency Management Agency Provincial Operations Centre (2020) IMT- Incident management team. CAN-TF2 Alberta. http://www.cantf2.com/imt-incident-management-team. Accessed 15 Nov 2020

2. Caldera HJ, Wirasinghe SC (2021) A universal severity classification for natural disasters. Nat Hazards. https://doi.org/10.1007/s11069-021-05106-9

3. Caldera HJ, Wirasinghe SC, Zanzotto L (2018) Severity scale for tornadoes. Nat Hazards 90(3):1051-1086. https://doi.org/10.1007/s11069-017-3084-z

4. Caldera HJ (2017) Analysis and classification of natural disasters. Dissertation, University of Calgary, Canada. https://doi.org/10.11575/PRISM/24811

5. Caldera HJ, Wirasinghe SC, Zanzotto L (2016a) NDM-528: An approach to classification of natural disasters by severity. In the proceedings of the 5th International Natural Disaster Mitigation Specialty Conference, Annual Conference of the Canadian Society for Civil Engineering, London, Canada, NDM-528, pp 1-11.

https://ir.lib.uwo.ca/csce2016/London/NaturalDisasterMitigation/20/

6. Caldera HJ, Ebadi O, Salari M, Wang L, Ghaffari M, Wirasinghe SC (2016b) The severity classification for tsunamis based on fatality analysis, In the proceedings of the 12th Annual Conference of the International Institute for Infrastructure Renewal and Reconstruction, Kandy, Sri Lanka, pp 1-9

7. Caldera HJ, Wirasinghe SC (2015a) Preliminary Analysis and Classification of Natural Disasters: Fatality Based Disaster Classification. Science and Technology Major Group Booth, The Third United Nations World Conference on Disaster Risk Reduction (3rd UN WCDRR), Sendai, Japan

8. Caldera HJ, Wirasinghe SC (2015b) Analysis and Classification of Natural Disasters. Poster Exhibition and Presentation in Public Forum Poster Session, The Third United Nations World Conference on Disaster Risk Reduction (3rd UN WCDRR), Sendai, Japan. http://www.wcdrr.org/conference/events/462

9. Caldera HJ, Wirasinghe SC (2014) Analysis and Classification of Volcanic Eruptions. In: Rapp RR, Harland W (eds) the proceedings of the 10th Annual Conference of the International Institute for Infrastructure Renewal and Reconstruction, West Lafayette, Indiana, pp 128-133. https://doi.org/10.5703/1288284315372

10. Camerer CF, Kunreuther H (1989) Decision processes for low probability events: policy implications. J of policy analysis and management 8(4):565-592

11. Centers for Disease Control and Prevention (CDC) (2020) Identifying the outbreak source. https://www.cdc.gov/coronavirus/2019-ncov/cases-updates/about-epidemiology/identifying-source-outbreak.html. Accessed 09 Dec 2020

12. Cresswell J (2009) The Oxford dictionary of word origins. Oxford University Press

13. de Boer J (1990) Definition and classification of disasters: Introduction of a disaster severity scale. J of Emerg Medicine 8(5):591-595

14. Durage SW, Kattan L, Wirasinghe SC, Ruwanpura JY (2014) Evacuation behaviour of households and drivers during a tornado: analysis based on a stated preference survey in Calgary, Canada. Nat Hazards 71(3):1495-1517

15. Eshghi K, Larson RC (2008) Disasters: lessons from the past 105 years. Disaster Prev Manage 17(1):62-82. https://doi.org/10.1108/09653560810855883

Page $19 / 30$ 
16. Fink A (2003a) Target populations and samples. How to sample in surveys. SAGE Publications, Inc., pp 2-23. https://dx.doi.org/10.4135/9781412984478

17. Fink A (2003b) Statistics and samples. How to sample in surveys. SAGE Publications, Inc., pp 24-60. https://dx.doi.org/10.4135/9781412984478

18. Gad-el-Hak M (2008) The art and science of large-scale disasters. In: Gad-el-Hak M (ed) Large-scale disasters. Cambridge University Press, New York, pp 5-68

19. Harper D (2001) Online Etymological Dictionary. http://www.etymonline.com/. Accessed 21 Nov 2014

20. Hayes A (2021) Nonparametric Method. Investopedia. https://www.investopedia.com/terms/n/nonparametricmethod.asp. Accessed 17 June 2021

21. Johns Hopkins University (2022) COVID-19 dashboard. Center for Systems Science and Engineering, Johns Hopkins Universityhttps://gisanddata.maps.arcgis.com/apps/opsdashboard/index.html\#/bda7594740fd40299423467b48e9ecf6. Accessed 24 January 2022

22. Johnson J (2021) Global digital population as of January 2021. Statista. https://www.statista.com/statistics/617136/digital-population-worldwide/. Accessed 17 June 2021

23. Kelman I (2008) Addressing the root causes of large-scale disasters. In: Gad-el-Hak M (ed) Large-scale disasters. Cambridge University Press, New York, pp 94-119

24. Lane J (2021) The 10 Most Spoken Languages In The World. Babbel Magazine. Published June 2,2021. https://www.babbel.com/en/magazine/the-10-most-spoken-languages-in-the-world

25. Löw P, Wirtz A (2010) Structure and needs of global loss databases of natural disasters. International Disaster and Risk Conference, Davos, Switzerland, pp 1-4

26. Lehmann EL (1998) Non-parametric: Statistical Methods Based on Ranks, ISBN = 978-0139977350, pp. 76-81. https://www.graphpad.com/guides/prism/latest/statistics/stat_sample_size_for_nonparametric_htm

27. Lyons D (2021) How Many People Speak English, And Where Is It Spoken?. Babbel Magazine. Published 10 March 2021. https://www.babbel.com/en/magazine/how-many-people-speak-english-and-where-is-it-spoken

28. Merriam-Webster (2013) Merriam- Webster Thesaurus. http://www.merriam-webster.com. Accessed 01 Jan. 2013

29. Meyer RJ (2006) Why we under-prepare for hazards? In: Daniels RJ, Kettl DF, Kunreuther H (eds) On risk and disaster: lessons from hurricane Katrina. University of Pennsylvania Press, Philadelphia, Pennsylvania, pp 153-173

30. Minitab (2015) Choosing Between a Nonparametric Test and a Parametric Test. In Hypothesis Testing, Statistics. Minitab Blog Editor. https://blog.minitab.com/en/adventures-in-statistics-2/choosing-between-a-nonparametric-test-and-aparametric-test. Accessed 20 Jan. 2022

31. Olsen GR, Carstensen N, Hoyen K (2003) Humanitarian crisis: what determines the level of emergency assistance? media coverage, donor interest and the aid business. Disasters 27(2):109-126

32. Oxford University (2014) The Oxford English dictionary. Oxford University Press. http://www.oed.com/. Accessed 21 Nov 2014

33. Oxford University (2010) In: Stevenson A (ed) Oxford Dictionary of English. Oxford University, Oxford University Press

34. Penuel KB, Statler M, Hagen R (2013) Encyclopedia of crisis management. SAGE Publications Inc, Thousand Oaks, Calif

35. Rutherford WH, de Boer J (1983) The definition and classification of disasters. Injury 15(1):10-12. https://doi.org/10.1016/0020-1383(83)90154-7

36. Shakespeare W (1600) Internet Shakespeare Editions. In: Gaby R (ed) Internet Shakespeare Editions. University of Victoria 37. Siegel S (1957) Nonparametric Statistics. Am Stat 11(3):13-19. https://doi.org/10.2307/2685679

38. Statistics Solutions (2021) Assumptions of the Wilcoxon Sign Test. Directory of Statistical Analyses, Complete Dissertation. https://www.statisticssolutions.com/free-resources/directory-of-statistical-analyses/assumptions-of-thewilcox-sign-test/. Accessed 05 July 2021 
39. Szmigiera M (2021) Proportion of selected age groups of world population in 2020, by region. Statista.

https://www.statista.com/statistics/265759/world-population-by-age-and-region/. Accessed 17 June 2021

40. Tierney K (2008) Hurricane Katrina: catastrophic impact and alarming lessons. In: Quigley JM, Rosenthal LA (eds) Risking house and home: disasters, cities, public policy. Berkely Public Policy Press, Institute of Governmental Stud Publications, Berkely, California, pp 119-136

41. United States Fire Administration (2020) An overview of incident management teams. The United States Department of Homeland Security, The Federal Emergency Management Agency.

https://www.usfa.fema.gov/training/imt/imt_overview.html. Accessed 8 Nov 2019

42. Wickramaratne S, Ruwanpura J, Ranasinghe U, Durage SW, Adikariwattage V, Wirasinghe SC (2012) Ranking of natural disasters in Sri Lanka for mitigation planning. Int J Disaster Resil Built Environ 3(2):115-132.

https://doi.org/10.1108/17595901211245198

43. Wirasinghe SC, Caldera HJ, Durage SW, Ruwanpura JY (2013a) Preliminary analysis and classification of natural disasters. In the proceedings of the 9th Annual Conference of the International Institute for Infrastructure Renewal and Reconstruction, Brisbane, Australia. pp 150-160. https://digitalcollections.qut.edu.au/2213/

44. Wirasinghe SC, Caldera HJ, Durage SW, Ruwanpura JY (2013b) Comparative analysis and classification of natural disasters, catastrophes and calamities. In the proceedings of the World Engineering Summit in the Institution of Engineers, Singapore, $\mathrm{pp} 7$

45. Wood D (2016) Calgary emergency management agency releases current list of top 10 hazards and risks in Calgary. Calgary Herald. http://calgaryherald.com/news/local-news/calgary-emergency-management-agency-releases-current-listof-top-10-hazards-and-risks-in-calgary. Accessed 3 Apr. 2016

46. World Health Organization (WHO) (2022) Global Situation in WHO Coronavirus (COVID-19) Dashboard. World Health Organization, Geneva. https://covid19.who.int/. Accessed 27 January 2022

47. World Health Organization (WHO) (2020) World Health Organization announces COVID-19 outbreak a pandemic. World Health Organization, Geneva. http://www.euro.who.int/en/health-topics/health-emergencies/coronavirus-covid19/news/news/2020/3/who-announces-covid-19-outbreak-a-pandemic. Accessed 12 March 2020

48. WHO (2020) Tracking SARS-CoV-2 variants. World Health Organization (WHO), Geneva. Updated on 24 January 2022. https://www.who.int/en/activities/tracking-SARS-CoV-2-variants/. Accessed 24 January 2022

49. World Bank (2022a) Population total. World Bank Open Data. http://data.worldbank.org/indicator/SP.POP.TOTL? end=2015\&start=1960\&view=chart. Accessed 29 Jan. 2022

50. World Bank (2022b) GDP (current US\$). World Bank national accounts data.

http://data.worldbank.org/indicator/NY.GDP.MKTP.CD . Accessed 29 Jan. 2022

51. Worldbank (2021) Individuals using the Internet (\% of population), International Telecommunication Union (ITU) World Telecommunication/ICT Indicators Database, The world Bank. https://data.worldbank.org/indicator/IT.NET.USER.ZS? end=2019\&name_desc=false\&start=1960\&view=chart. Accessed 17 June 2021

52. Yew YY, Castro Delgado RJ, Arcos González P, Heslop D (2019) The Yew disaster severity index: a new tool in disaster metrics. Prehosp Disaster Med 34(1):98-103

\section{Tables}

Table 1 Etymological definition

\begin{tabular}{lll}
\hline Terminology & \multicolumn{1}{c}{ Meaning } & \multicolumn{1}{c}{ Origin Time } \\
\hline Apocalypse & Uncover, disclose, reveal ${ }^{3}$ & Late 14th century \\
Calamity & Damage, loss, failure, disaster, misfortune, adversity ${ }^{3}$ & ${\text { Early } 15^{\text {th }} \text { century }}^{3}$ \\
Cataclysm & To wash down ${ }^{1,2,3}$ (deluge, flood, inundation) ${ }^{3}$ & Early 17th century (the 1630s) \\
Catastrophe & Overturning, sudden turn $^{2,3}$ (a sudden end) ${ }^{3}$ & Mid 16th century (the 1530s) \\
Disaster & Ill-started event (the stars are against you) $^{1}$ & Late 16th century (the 1590s) \\
Emergency & To rise out or up (unforeseen occurrence requiring immediate attention) ${ }^{3}$ Mid 17th century (the 1630s) \\
\hline
\end{tabular}

Page 21/30 
Source: ${ }^{1}$ (Cresswell 2009); ${ }^{2}$ (Oxford University Press 2014); ${ }^{3}$ (Harper 2001)

Table 2 Current English dictionary definition

\begin{tabular}{ll}
\hline Terminology & \multicolumn{1}{c}{ Meaning } \\
\hline Apocalypse & an event involving destruction or damage on a catastrophic scale. \\
Calamity & An event causing great and often sudden damage or distress; a disaster. \\
Cataclysm & A large-scale and violent event in the natural world. \\
Catastrophe & An event causing great and usually sudden damage or suffering; a disaster. \\
Disaster & A sudden accident or a natural catastrophe that causes great damage or loss of life. \\
Emergency & A serious, unexpected, and often dangerous situation requiring immediate action. \\
\hline
\end{tabular}

Source: (Oxford University 2010)

Table 3 Number of response rankings collected for natural disaster terminologies

\begin{tabular}{lccccc}
\hline Terminology & $\mathbf{N}$ & Missing & Median & Interquartile Range & Mean Rank \\
\hline Calamity & 682 & 488 & 3 & $2-4$ & 2.72 \\
Cataclysm & 638 & 532 & 5 & $3-5$ & 3.63 \\
Catastrophe & 775 & 395 & 4 & $3-5$ & 3.59 \\
Disaster & 800 & 370 & 2 & $2-4$ & 2.95 \\
Emergency & 799 & 371 & 1 & $1-3$ & 2.11 \\
\hline
\end{tabular}

Table 4 The test statistics of the Wilcoxon signed-rank test for pairwise samples

\begin{tabular}{lcccccl}
\hline \multicolumn{1}{c}{ Paired sample } & $\mathbf{M}_{\mathrm{A}}-\mathrm{M}_{\mathrm{B}}$ & $\mathrm{W}^{-}$ & $\mathrm{W}^{+}$ & $\mathrm{Z}$ & P-Value & \multicolumn{1}{c}{ Results } \\
\hline Emergency - Calamity & -2 & 408 & 216 & $-7.642^{\mathrm{b}}$ & 0.000 & Emergency < Calamity \\
Emergency - Disaster & -1 & 460 & 164 & $-10.898^{\mathrm{b}}$ & 0.000 & Emergency < Disaster \\
Emergency - Catastrophe & -3 & 471 & 153 & $-12.479^{\mathrm{b}}$ & 0.000 & Emergency < Catastrophe \\
Emergency - Cataclysm & -4 & 464 & 160 & $-11.535^{\mathrm{b}}$ & 0.000 & Emergency < Cataclysm \\
Disaster - Calamity & -1 & 297 & 327 & $-3.022^{\mathrm{a}}$ & 0.003 & Calamity < Disaster \\
Catastrophe - Calamity & 1 & 191 & 433 & $-9.893^{\mathrm{a}}$ & 0.000 & Calamity < Catastrophe \\
Cataclysm - Calamity & 2 & 180 & 444 & $-10.356^{\mathrm{a}}$ & 0.000 & Calamity < Cataclysm \\
Disaster - Catastrophe & -2 & 420 & 204 & $-9.244^{\mathrm{b}}$ & 0.000 & Disaster < Catastrophe \\
Disaster - Cataclysm & -3 & 400 & 224 & $-7.624^{\mathrm{b}}$ & 0.000 & Disaster < Cataclysm \\
Catastrophe - Cataclysm & -1 & 331 & 293 & $-.492^{\mathrm{b}}$ & 0.623 & Catastrophe = Cataclysm \\
\hline
\end{tabular}

${ }^{\mathrm{a}}$ based on negative ranks; ${ }^{\mathrm{b}}$ based on positive ranks.

Table 5 Wilcoxon signed-rank test results for pairwise samples of lexical (verbal) meaning 


\begin{tabular}{|c|c|c|c|c|}
\hline Global $(\mathrm{N}=624)$ & $\begin{array}{c}\text { North America } \\
(\mathrm{N}=434)\end{array}$ & Asia $(\mathrm{N}=125)$ & Europe $(\mathrm{N}=31)$ & Oceania $(\mathrm{N}=25)$ \\
\hline $\begin{array}{l}\text { Emg. }< \\
\text { Cal. }(\mathrm{P}=0.000)\end{array}$ & $\begin{array}{l}\text { Emg. }< \\
\text { Cal. }(\mathrm{P}<0.001)\end{array}$ & $\begin{array}{l}\text { Emg. }< \\
\text { Cal. }(\mathrm{P}=0.001)\end{array}$ & Emg. $=$ Cal. $\quad(P=0.067)$ & Emg. $=$ Cal. $\quad(P=0.019)$ \\
\hline Emg. $<$ Dis. $(\mathrm{P}=0.000)$ & Emg. $<$ Dis. $(\mathrm{P}<0.001)$ & Emg. $<$ Dis. $(\mathrm{P}<0.001)$ & Emg. $<$ Dis. $(\mathrm{P}<0.001)$ & Emg. $<$ Dis. $(\mathrm{P}=0.003)$ \\
\hline $\begin{array}{l}\text { Emg. < Ctstrp. } \\
(\mathrm{P}=0.000)\end{array}$ & $\begin{array}{l}\text { Emg. < Ctstrp. } \\
(\mathrm{P}<0.001)\end{array}$ & $\begin{array}{l}\text { Emg. < Ctstrp. } \\
(\mathrm{P}<0.001)\end{array}$ & Emg. < Ctstrp. $(\mathrm{P}<0.001)$ & Emg. $=$ Ctstrp. $(\mathrm{P}=0.007)$ \\
\hline $\begin{array}{l}\text { Emg. < Ctclsm. } \\
(\mathrm{P}=0.000)\end{array}$ & $\begin{array}{l}\text { Emg. < Ctclsm. } \\
(\mathrm{P}<0.001)\end{array}$ & $\begin{array}{l}\text { Emg. < Ctclsm. } \\
(\mathrm{P}<0.001)\end{array}$ & Emg. < Ctclsm. $(\mathrm{P}<0.001)$ & Emg. $=$ Ctclsm. $(P=0.012)$ \\
\hline Cal. < Dis. $(\mathrm{P}=0.003)$ & Cal. $=$ Dis. $(P=0.042)$ & Cal. $=$ Dis. $(P=0.179)$ & Cal. $=$ Dis. $(P=0.038)$ & Cal. $=$ Dis. $(P=0.504)$ \\
\hline $\begin{array}{l}\text { Cal. < Ctstrp. } \\
(\mathrm{P}=0.000)\end{array}$ & $\begin{array}{l}\text { Cal. }<\text { Ctstrp. } \\
(\mathrm{P}<0.001)\end{array}$ & $\begin{array}{l}\text { Cal. }<\text { Ctstrp. } \\
(\mathrm{P}<0.001)\end{array}$ & Cal. < Ctstrp. $(\mathrm{P}<0.001)$ & Cal. = Ctstrp. $(P=0.126)$ \\
\hline $\begin{array}{l}\text { Cal. < Ctclsm. } \\
(\mathrm{P}=0.000)\end{array}$ & $\begin{array}{l}\text { Cal. < Ctclsm. } \\
(\mathrm{P}<0.001)\end{array}$ & $\begin{array}{l}\text { Cal. < Ctclsm } \\
(\mathrm{P}<0.001)\end{array}$ & Cal. $<$ Ctclsm. $(\mathrm{P}<0.001)$ & Cal. $=$ Ctclsm. $(P=0.179)$ \\
\hline $\begin{array}{l}\text { Dis. < Ctstrp. } \\
(\mathrm{P}=0.000)\end{array}$ & $\begin{array}{l}\text { Dis. < Ctstrp. } \\
(\mathrm{P}<0.001)\end{array}$ & $\begin{array}{l}\text { Dis. < Ctstrp. } \\
(\mathrm{P}<0.001)\end{array}$ & Dis. $=$ Ctstrp. $(P=0.008)$ & Dis. = Ctstrp. $(P=0.206)$ \\
\hline $\begin{array}{l}\text { Dis. < } \\
\text { Ctclsm. }(\mathrm{P}=0.000)\end{array}$ & $\begin{array}{l}\text { Dis. }< \\
\text { Ctclsm. }(\mathrm{P}<0.001)\end{array}$ & $\begin{array}{l}\text { Dis. }= \\
\text { Ctclsm. }(P=0.014)\end{array}$ & Dis. $=$ Ctclsm. $(P=0.017)$ & Dis. $=$ Ctclsm. $(P=0.526)$ \\
\hline $\begin{array}{l}\text { Ctstrp. = Ctclsm. } \\
(\mathrm{P}=0.623)\end{array}$ & $\begin{array}{l}\text { Ctstrp. }= \\
\text { Ctclsm. }(\mathrm{P}=0.071)\end{array}$ & $\begin{array}{l}\text { Ctstrp. }= \\
\text { Ctclsm. }(\mathrm{P}=0.048)\end{array}$ & Ctstrp. $=$ Ctclsm. $(\mathrm{P}=0.360)$ & Ctstrp. $=$ Ctclsm. $(P=0.392)$ \\
\hline
\end{tabular}

Emg. = Emergency; Cal. = Calamity; Dis. $=$ Disaster; Ctstrp. $=$ Catastrophe; Ctclsm. $=$ Cataclysm

Table 6 The level of seriousness of the five (5) terminologies according to different sample

\begin{tabular}{|c|c|c|c|c|c|c|}
\hline \multirow[t]{2}{*}{ Terminology } & \multirow{2}{*}{$\begin{array}{l}\text { Entire Sample }(\mathrm{N}=1170 \text { or } \\
\text { 808) }\end{array}$} & \multicolumn{5}{|c|}{ Complete ranking $(\mathrm{N}=624)$} \\
\hline & & $\begin{array}{c}\text { Global } \\
(\mathrm{N}=624)\end{array}$ & $\begin{array}{c}\text { North America } \\
(\mathrm{N}=434)\end{array}$ & $\begin{array}{c}\text { Asia } \\
(\mathrm{N}=125)\end{array}$ & $\begin{array}{l}\text { Europe } \\
(\mathrm{N}=31)\end{array}$ & $\begin{array}{c}\text { Oceania } \\
(\mathrm{N}=25)\end{array}$ \\
\hline Emergency & Rank 1 & Rank 1 & Rank 1 & Rank 1 & Rank 1 & Rank 1 \\
\hline Calamity & Rank 2 & Rank 2 & Rank 2 & Rank 2 & Rank 1 & Rank 1 \\
\hline Disaster & Rank 3 & Rank 3 & Rank 2 & Rank 2 & Rank 2 & Rank 1 \\
\hline Catastrophe & Rank 4 & Rank 4 & Rank 3 & Rank 3 & Rank 2 & Rank 1 \\
\hline Cataclysm & Rank 4 & Rank 4 & Rank 3 & Rank 3 & Rank 2 & Rank 1 \\
\hline
\end{tabular}

Table 7 The Mean Rank of the samples

\begin{tabular}{|c|c|c|c|c|c|c|c|c|c|c|}
\hline \multirow[t]{2}{*}{ Terminology } & \multicolumn{5}{|c|}{ Lexical (Verbal) Meaning Mean Rank (Order) } & \multicolumn{5}{|c|}{ Lexicon (Dictionary) Meaning Mean Rank (Order) } \\
\hline & Global & North America & Asia & Europe & Oceania & Global & North America & Asia & Europe & Oceania \\
\hline Eme & $2.11(1)$ & $2.16(1)$ & $2.15(1)$ & 1.71 & & 2.6 & & 2.72 & 2.2 & \\
\hline & $2.72(2)$ & 2) & 2) & 2.3 & & 2.6 & & 2.7 & 2.39 & \\
\hline Disa & $2.95(3)$ & $92(3)$ & $2.97(3)$ & $3.06(3)$ & 3.2 & 3.09 & & (3) & 3.19 (3) & (3) \\
\hline Catast & 3.59 (4) & $3.53(4)$ & 3.70 & 3.77 (4) & & 3.22 & & $3.22(4)$ & 3.39 (4) & $3.02(2)$ \\
\hline Cataclysm & $3.63(5)$ & 3.67 (5) & $3.42(4)$ & $4.10(5)$ & $3.40(4)$ & $3.35(5)$ & $3.28(5)$ & 3.29 (5) & $3.81(5)$ & $3.41(4)$ \\
\hline
\end{tabular}

Table 8 The test statistics of the Friedman test and Kendall's W Test

\begin{tabular}{|c|c|c|c|c|c|c|c|c|c|c|}
\hline & \multicolumn{5}{|c|}{ Lexical (Verbal) Meaning } & \multicolumn{5}{|c|}{ Lexicon (Dictionary) Meaning } \\
\hline & Global & $\begin{array}{c}\text { North } \\
\text { America }\end{array}$ & Asia & Europe & Oceania & Global & $\begin{array}{c}\text { North } \\
\text { America }\end{array}$ & Asia & Europe & Oceania \\
\hline $\mathrm{N}$ & 624 & 434 & 125 & 31 & 25 & 443 & 145 & 181 & 57 & 44 \\
\hline $\begin{array}{c}\text { Kendall's Coefficient of } \\
\text { Concordance }\end{array}$ & .161 & 0.152 & .145 & .389 & .196 & 0.041 & 0.035 & 0.027 & 0.181 & 0.033 \\
\hline Chi-Square & 402.397 & 263.006 & 72.320 & 48.206 & 19.616 & 71.975 & 20.182 & 19.549 & 41.277 & 5.800 \\
\hline Degree of Freedom & 4 & 4 & 4 & 4 & 4 & 4 & 4 & 4 & 4 & 4 \\
\hline Friedman test $\mathrm{P}$ value & .000 & $<0.001$ & $<0.001$ & $<0.001$ & $<0.001$ & 0.000 & $<0.001$ & 0.001 & 0.000 & 0.215 \\
\hline Kendall's W Test P value & .000 & $<0.001$ & $<0.001$ & $<0.001$ & $<0.001$ & 0.000 & $<0.001$ & 0.001 & 0.000 & 0.215 \\
\hline
\end{tabular}

Table 9 The results of the Wilcoxon signed-rank test for pairwise samples with definitions 


\begin{tabular}{|c|c|c|c|c|}
\hline Global (N=443) & North America $(\mathrm{N}=145)$ & Asia $(\mathrm{N}=181)$ & Europe $(\mathrm{N}=57)$ & Oceania $(\mathrm{N}=44)$ \\
\hline Emg. $=$ Cal. $(P=0.942)$ & Emg. = Cal. $(\mathrm{P}=0.718)$ & Emg. $=$ Cal. $(\mathrm{P}=0.904)$ & Emg. $=$ Cal. $(P=0.549)$ & Emg. $=$ Cal. $(P=0.897)$ \\
\hline Emg. < Dis. $(\mathrm{P}=0.000)$ & Emg. < Dis. $(\mathrm{P}=0.004)$ & Emg. $=$ Dis. $(P=0.085)$ & Emg. $<$ Dis. $(\mathrm{P}=0.000)$ & Emg. $=$ Dis. $(P=0.253)$ \\
\hline Emg. $<$ Ctstrp. $(\mathrm{P}=0.000)$ & Emg. < Ctstrp. $(\mathrm{P}=0.001)$ & Emg. $=$ Ctstrp. $(\mathrm{P}=0.008)$ & Emg. < Ctstrp. $(\mathrm{P}=0.001)$ & Emg. $=$ Ctstrp. $(P=0.364)$ \\
\hline Emg. $<$ Ctclsm $(\mathrm{P}=0.000)$ & Emg. $<$ Ctclsm $(P=0.004)$ & Emg. $=$ Ctclsm $(P=0.014)$ & Emg. $<$ Ctclsm $(\mathrm{P}=0.000)$ & Emg. $=$ Ctclsm $(P=0.090)$ \\
\hline Cal. < Dis. $(\mathrm{P}=0.000)$ & Cal. $=$ Dis. $(P=0.047)$ & Cal. $=$ Dis. $(\mathrm{P}=0.118)$ & Cal. $=$ Dis. $(P=0.010)$ & Cal. = Dis. $(\mathrm{P}=0.309)$ \\
\hline Cal. < Ctstrp. $(\mathrm{P}=0.000)$ & Cal. < Ctstrp. $(\mathrm{P}=0.002)$ & Cal. < Ctstrp. $(\mathrm{P}=0.000)$ & Cal. $<$ Ctstrp. $(\mathrm{P}=0.000)$ & Cal. $=$ Ctstrp. $(P=0.249)$ \\
\hline Cal. $<$ Ctclsm $(\mathrm{P}=0.000)$ & Cal. $<$ Ctclsm $(\mathrm{P}<0.001)$ & Cal. $<$ Ctclsm $(\mathrm{P}=0.000)$ & Cal. $<$ Ctclsm & Cal. $=$ Ctclsm $(P=0.013)$ \\
\hline Dis. $=$ Ctstrp. $(P=0.109)$ & Dis. $=$ Ctstrp. $(P=0.189)$ & Dis. $=$ Ctstrp. $(P=0.118)$ & Dis. $=$ Ctstrp. $(P=0.312)$ & Dis. $=$ Ctstrp. $(P=0.743)$ \\
\hline Dis. $=$ Ctclsm $(\mathrm{P}=0.023)$ & Dis. $=$ Ctclsm $(P=0.298)$ & Dis. $=$ Ctclsm $(P=0.107)$ & Dis. $=$ Ctclsm $(P=0.049)$ & Dis. $=$ Ctclsm $(P=0.390)$ \\
\hline $\begin{array}{l}\text { Ctstrp. = Ctclsm } \\
\quad(P=0.129)\end{array}$ & $\begin{array}{c}\text { Ctstrp. }= \\
\text { Ctclsm }(\mathrm{P}=0.888)\end{array}$ & $\begin{array}{c}\text { Ctstrp. }= \\
\text { Ctclsm }(\mathrm{P}=0.578)\end{array}$ & $\begin{array}{c}\text { Ctstrp. }= \\
\text { Ctclsm }(\mathrm{P}=0.042)\end{array}$ & $\begin{array}{c}\text { Ctstrp. }= \\
\text { Ctclsm }(\mathrm{P}=0.090)\end{array}$ \\
\hline
\end{tabular}

Emg. = Emergency; Cal. = Calamity; Dis. $=$ Disaster; Ctstrp. $=$ Catastrophe; Ctclsm. $=$ Cataclysm

Table 10 The level of seriousness of the five (5) terminologies according to different sample

\begin{tabular}{|c|c|c|c|c|c|c|c|c|c|c|}
\hline \multirow[t]{2}{*}{ Terminology } & \multicolumn{5}{|c|}{ Lexical (Verbal) Meaning } & \multicolumn{5}{|c|}{ Lexicon (Dictionary) Meaning } \\
\hline & Global & North America & Asia & Europe & Oceania & Global & North America & Asia & Europe & Oce \\
\hline Eme & Rank 1 & Rank 1 & Rank 1 & Ran & & Rank 1 & & Rank 1 & & \\
\hline Calamity & Rank 2 & & Rank 2 & k 1 & & $\mathrm{k} 1$ & & $\mathrm{k} 1$ & & \\
\hline Disaster & Rank 3 & & Rank 2 & Rank 2 & & $\mathrm{k} 2$ & & $\mathrm{nk} 1$ & $\mathrm{k} 2$ & k 1 \\
\hline Catastrophe & Rank 4 & Rank 3 & Rank 3 & Rank 2 & Ranl & Rank 2 & & Rank 1 & k 2 & Rank 1 \\
\hline Cataclysm & Rank 4 & Rank 3 & Rank 3 & Rank 2 & Rank 1 & Rank 2 & Rank 2 & Rank 1 & Rank 2 & Rank 1 \\
\hline
\end{tabular}

Table 11 Covid-19 statistics

\begin{tabular}{lllll}
\hline Date & 21 September 2020 & 25 January 2021 & 26 April 2021 & 28 June 2021 \\
\hline Global Confirmed Cases & 33.487 million & 102.574 million & 151.654 million & 183.282 million \\
Global Fatalities & 1.071 million & 2.333 million & 3.318 million & 3.981 million \\
\hline
\end{tabular}

Source: (World 2022)

Table 12 Natural disaster terminologies and their change in perception

\begin{tabular}{cccccc}
\hline Level & Etymology & Dictionary & \multicolumn{2}{c}{ People's Perception } & Proposed Terminology \\
\cline { 3 - 5 } & & & Lexical (without definition) & Lexicon (with definition) & Emergency \\
\hline 1 & Emergency & Emergency & Emergency & Emergency/Calamity & Calamity \\
2 & Apocalypse & Disaster & Calamity & Disaster/Catastrophe/ Cataclysm & Disaster \\
3 & Calamity & Calamity & Disaster & Catastrophe \\
4 & Cataclysm & Catastrophe & Catastrophe/ Cataclysm & Cataclysm \\
5 & Catastrophe & Cataclysm & & \\
6 & Disaster & Apocalypse & & \\
\hline
\end{tabular}

Table 13 Ranges of human and damage factors in 0-10 levels 


\begin{tabular}{lll}
\hline & Human factors $(\mathrm{H})$ & Damage factors (D) \\
\hline 0 & $0=\mathrm{H}$ & $0=\mathrm{D}$ \\
1 & $1<\mathrm{H} \leq 10$ & $1<\mathrm{D} \leq 10$ \\
& & $10<\mathrm{D} \leq 100$ \\
& & $100<\mathrm{D} \leq 1,000$ \\
& & $1,000<\mathrm{D} \leq 10,000$ \\
2 & $10<\mathrm{H} \leq 100$ & $10,000<\mathrm{D} \leq 100,000$ \\
3 & $100<\mathrm{H} \leq 1,000$ & $100,000<\mathrm{D} \leq 1$ Million \\
4 & $1,000<\mathrm{H} \leq 10,000$ & 1 Million $<\mathrm{D} \leq 10$ Million \\
5 & $10,000<\mathrm{H} \leq 100,000$ & 10 Million $<\mathrm{D} \leq 100$ Million \\
6 & $100,000<\mathrm{H} \leq 1 \mathrm{Million}$ & 100 Million $<\mathrm{D} \leq 1$ Billion \\
7 & $1 \mathrm{Million}<\mathrm{H} \leq 10$ Million & 1 Billion $<\mathrm{D} \leq 10$ Billion \\
8 & 10 Million $<\mathrm{H} \leq 100$ Million & 10 Billion $<\mathrm{D} \leq 100$ Billion \\
9 & 100 Million $<\mathrm{H} \leq 1$ Billion & 100 Billion $<\mathrm{D} \leq 1$ Trillion \\
10 & 1 Billion $<\mathrm{H}$ & 1 Trillion $<\mathrm{D}$ \\
\hline
\end{tabular}

Source: (Caldera and Wirasinghe 2021)

Table 14. Advanced Qualitative Universal Disaster Severity Classification

\begin{tabular}{|c|c|c|}
\hline $\begin{array}{l}\text { Severity } \\
\text { Level }\end{array}$ & $\begin{array}{c}\text { Proposed } \\
\text { Terminology }\end{array}$ & Proposed Definition \\
\hline UDSCS 0 & $\begin{array}{l}\text { Emergency } \\
\text { Level } 1\end{array}$ & A sudden natural event that causes substantial damage, injuries, and some/no fatalities \\
\hline UDSCS 1 & $\begin{array}{l}\text { Emergency } \\
\text { Level } 2\end{array}$ & \\
\hline UDSCS 2 & $\begin{array}{l}\text { Calamity Level } \\
1\end{array}$ & A major natural event that causes significant damage, many serious injuries, and many fatalities \\
\hline UDSCS 3 & $\begin{array}{l}\text { Calamity Level } \\
\qquad 2\end{array}$ & \\
\hline UDSCS 4 & Disaster Level 1 & A large-scale natural disturbance that causes severe destruction, a major number of injuries, and \\
\hline UDSCS 5 & Disaster Level 2 & a great number of fatalities \\
\hline UDSCS 6 & $\begin{array}{l}\text { Catastrophe } \\
\text { Level } 1\end{array}$ & $\begin{array}{l}\text { A very large-scale natural disturbance that causes widespread continental destruction, a massive } \\
\text { number of injuries, and an extensive loss of life }\end{array}$ \\
\hline UDSCS 7 & $\begin{array}{l}\text { Catastrophe } \\
\text { Level } 2\end{array}$ & \\
\hline UDSCS 8 & $\begin{array}{l}\text { Cataclysm Level } \\
1\end{array}$ & $\begin{array}{c}\text { An extremely large-scale natural upheaval that causes global devastation, an uncountable number } \\
\text { of injuries, and unimaginable loss of life }\end{array}$ \\
\hline UDSCS 9 & $\begin{array}{l}\text { Cataclysm Level } \\
\qquad 2\end{array}$ & \\
\hline $\begin{array}{l}\text { UDSCS } \\
10\end{array}$ & $\begin{array}{l}\text { Partial or Full } \\
\text { Extinction }\end{array}$ & A world-scale natural upheaval that causes universal devastation, partial or full extinction of humans \\
\hline
\end{tabular}

Table 15 Modified Universal Disaster Severity Classification - Fatality based 


\begin{tabular}{|c|c|c|c|c|c|}
\hline \multirow{2}{*}{$\begin{array}{l}\text { Severity level } \\
\text { and colour code }\end{array}$} & \multicolumn{2}{|r|}{ Qualitative } & \multicolumn{3}{|c|}{ Quantitative } \\
\hline & $\begin{array}{l}\text { Proposed } \\
\text { word }\end{array}$ & Definition & $\begin{array}{l}\text { Fatalities } \\
\text { (F) }\end{array}$ & Probability $^{\mathrm{a}}$ & Example \\
\hline UDSCS 0 & $\begin{array}{l}\text { Emergency } \\
\text { Level } 1\end{array}$ & $\begin{array}{l}\text { A sudden natural event that } \\
\text { causes substantial damage, injuries, and some/no fatalities }\end{array}$ & $\mathrm{F}<1$ & $18.79 \%$ & $\begin{array}{l}\text { Fort McMurray } \\
\text { Fire, Canada } \\
\text { (2016) - 0 } \\
\text { direct deaths } \\
\text { and } 2 \text { indirect } \\
\text { deaths }\end{array}$ \\
\hline UDSCS 1 & $\begin{array}{l}\text { Emergency } \\
\text { Level } 2\end{array}$ & & $\begin{array}{l}1 \leq \mathrm{F}< \\
10\end{array}$ & $4.20 \%$ & $\begin{array}{l}\text { Alberta Flood, } \\
\text { Canada (2013) } \\
\text { - } 5 \text { deaths }\end{array}$ \\
\hline UDSCS 2 & $\begin{array}{l}\text { Calamity } \\
\text { Level } 1\end{array}$ & $\begin{array}{l}\text { A major natural event that causes significant damage, } \\
\text { many serious injuries, and many fatalities }\end{array}$ & $\begin{array}{l}10 \leq \mathrm{F}< \\
100\end{array}$ & $29.11 \%$ & $\begin{array}{l}\text { Edmonton } \\
\text { tornado, } \\
\text { Canada (1987) } \\
-27 \text { deaths }\end{array}$ \\
\hline UDSCS 3 & $\begin{array}{l}\text { Calamity } \\
\text { Level } 2\end{array}$ & & $\begin{array}{l}100 \leq \mathrm{F} \\
<1,000\end{array}$ & $39.37 \%$ & $\begin{array}{l}\text { Thailand flood } \\
\text { (2011) - } 815 \\
\text { deaths }\end{array}$ \\
\hline UDSCS 4 & $\begin{array}{l}\text { Disaster } \\
\text { Level } 1\end{array}$ & $\begin{array}{l}\text { A large-scale natural disturbance that } \\
\text { causes severe destruction, a major number } \\
\text { of injuries, and a great number of fatalities }\end{array}$ & $\begin{array}{l}1,000 \leq \\
F< \\
10,000\end{array}$ & $7.75 \%$ & $\begin{array}{l}\text { Hurricane } \\
\text { Katrina, USA } \\
(2005)-1,833 \\
\text { deaths }\end{array}$ \\
\hline UDSCS 5 & $\begin{array}{l}\text { Disaster } \\
\text { Level } 2\end{array}$ & & $\begin{array}{l}10,000 \leq \\
\mathrm{F}<0.1 \\
\mathrm{M}\end{array}$ & $0.72 \%$ & $\begin{array}{l}\text { Tohuku } \\
\text { earthquake } \\
\text { and tsunami, } \\
\text { Japan (2011) - } \\
\text { 15,882 deaths }\end{array}$ \\
\hline UDSCS 6 & $\begin{array}{l}\text { Catastrophe } \\
\text { Level } 1\end{array}$ & $\begin{array}{l}\text { A very large-scale natural disturbance that } \\
\text { causes widespread continental destruction, A massive } \\
\text { number of injuries, and an extensive loss of life }\end{array}$ & $\begin{array}{l}0.1 \mathrm{M} \leq \\
\mathrm{F}<1 \mathrm{M}\end{array}$ & $0.06 \%$ & $\begin{array}{l}\text { Haiti } \\
\text { earthquake } \\
(2010)- \\
316,000 \text { deaths }\end{array}$ \\
\hline UDSCS 7 & $\begin{array}{l}\text { Catastrophe } \\
\text { Level } 2\end{array}$ & & $\begin{array}{l}1 \mathrm{M} \leq \mathrm{F} \\
<10 \mathrm{M}\end{array}$ & $4.99 * 10^{-03} \%$ & $\begin{array}{l}\text { China floods } \\
(1931) \text { - more } \\
\text { than 2,500,000 } \\
\text { deaths } \\
\text { Asian Flu } \\
\text { pandemic } \\
\text { (1957-1958) - } \\
\text { more than } 1 \\
\text { million deaths }\end{array}$ \\
\hline UDSCS 8 & $\begin{array}{l}\text { Cataclysm } \\
\text { Level } 1\end{array}$ & $\begin{array}{l}\text { An extremely large-scale natural upheaval that } \\
\text { causes global devastation, an uncountable number } \\
\text { of injuries, and unimaginable loss of life }\end{array}$ & $\begin{array}{l}10 \mathrm{M} \leq \mathrm{F} \\
<100 \mathrm{M}\end{array}$ & $4.13 * 10^{-04} \%$ & $\begin{array}{l}\text { Spanish Flu } \\
\text { pandemic } \\
\text { (1918 - 1920) } \\
\text { over } 40 \text { million } \\
\text { deaths } \\
\text { Black death } \\
\text { pandemic } \\
\text { (1346 - 1353) - } \\
\text { over } 50 \text { million } \\
\text { estimated } \\
\text { deaths }\end{array}$ \\
\hline UDSCS 9 & $\begin{array}{l}\text { Cataclysm } \\
\text { Level } 2\end{array}$ & & $\begin{array}{l}100 \mathrm{M} \leq \\
\mathrm{F}<1 \mathrm{~B}\end{array}$ & $3.42 * 10^{-05} \%$ & $\begin{array}{l}\text { Super Volcano } \\
\text { (e.g., } \\
\text { Yellowstone) - } \\
\text { less than } 1 \\
\text { billion } \\
\text { estimated } \\
\text { deaths }\end{array}$ \\
\hline UDSCS 10 & Partial or & A world-scale natural upheaval that & $1 \mathrm{~B} \leq \mathrm{F}$ & $3.08 * 10^{-06} \%$ & Asteroid strike \\
\hline
\end{tabular}


Full

Extinction causes universal devastation, partial or full extinction of humans (diameter >

$1.5 \mathrm{~km}$ ) - less

than 1.5 billion

estimated

deaths

Pandemic

(Avian

influenza) -

less than 2.8

billion

estimated

deaths

$\mathrm{M}=$ Million; $\mathrm{B}=$ Billion

a Estimated approximate probabilities according to the fitted GED of $70^{\text {th }}$ order statistic

\section{Figures}

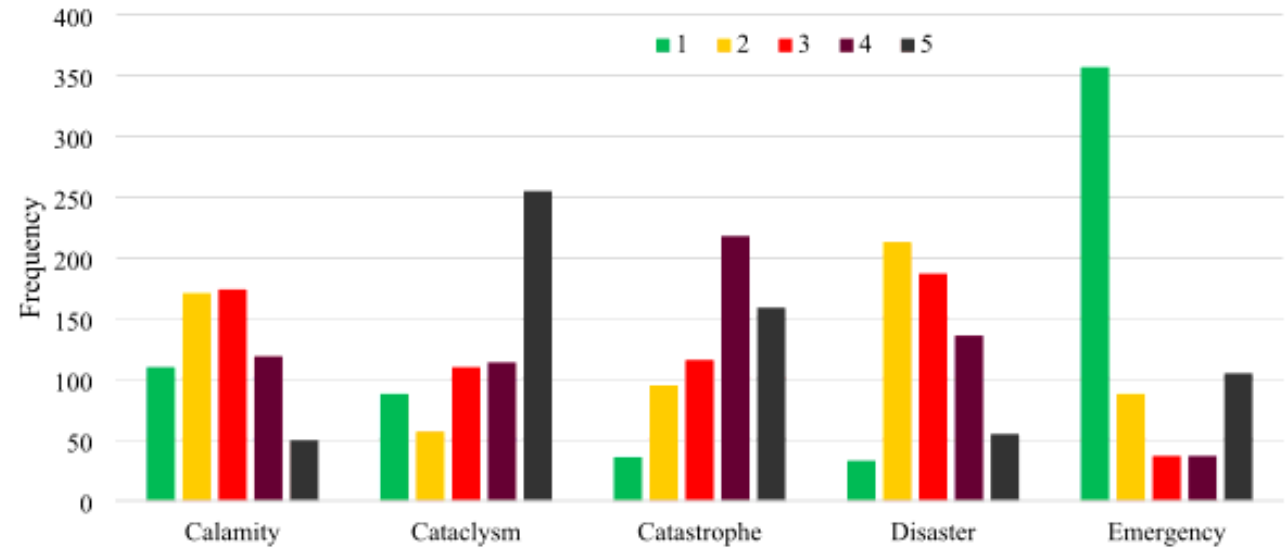

Figure 1

Respondent ranks for Natural Disaster Terminologies

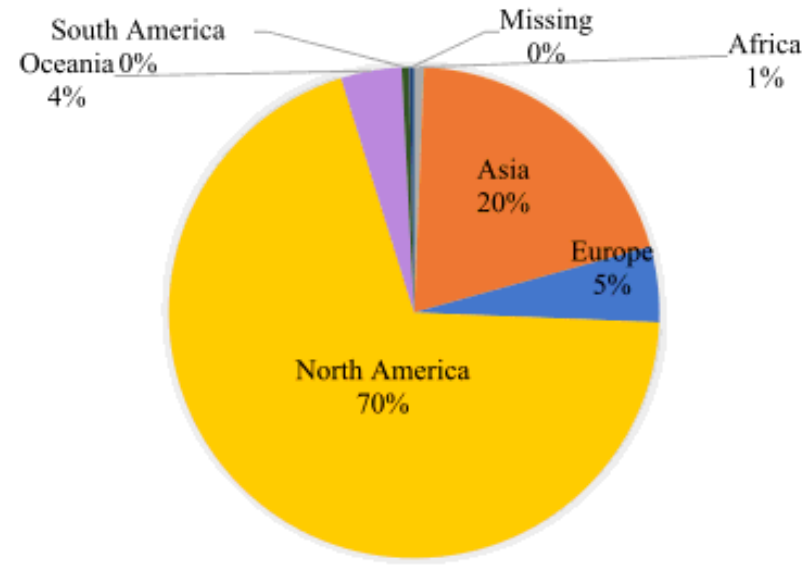

\section{Figure 2}

Geographical distribution 


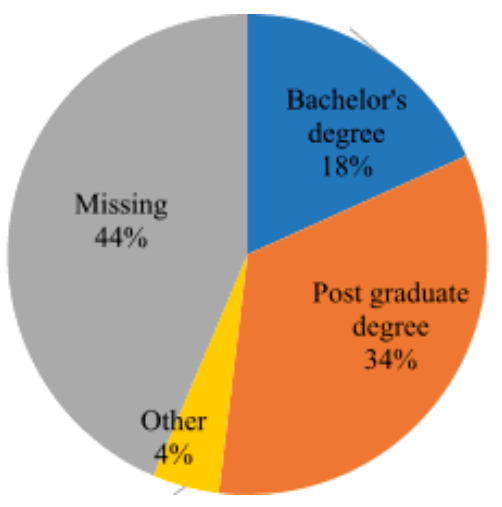

\section{Figure 3}

Education level distribution

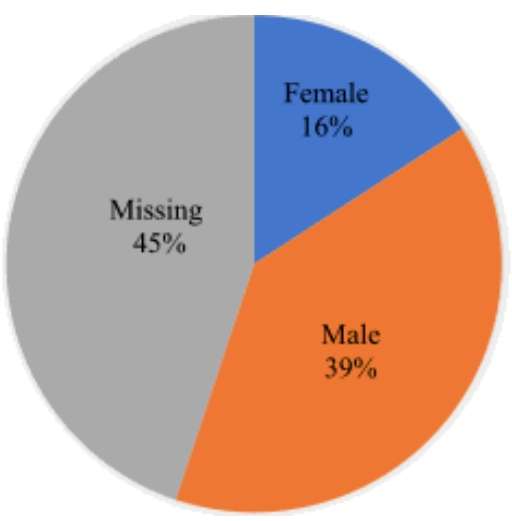

Figure 4

Gender distribution

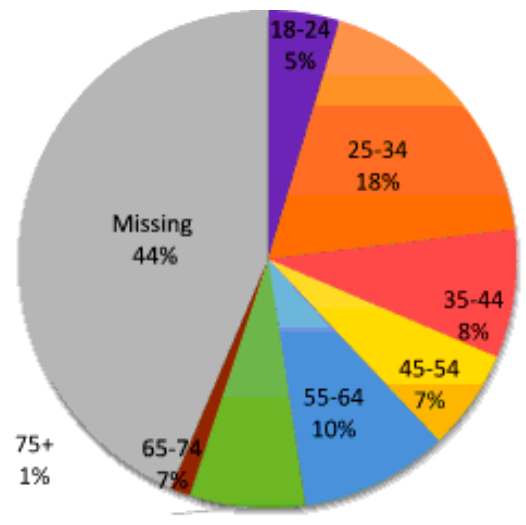

Figure 5

Age distribution 


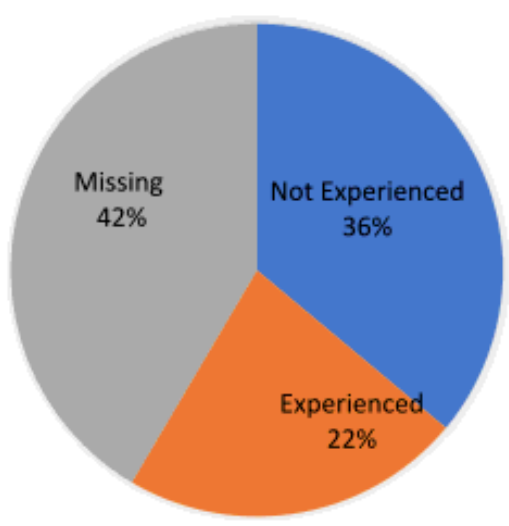

\section{Figure 6}

Disaster experience distribution

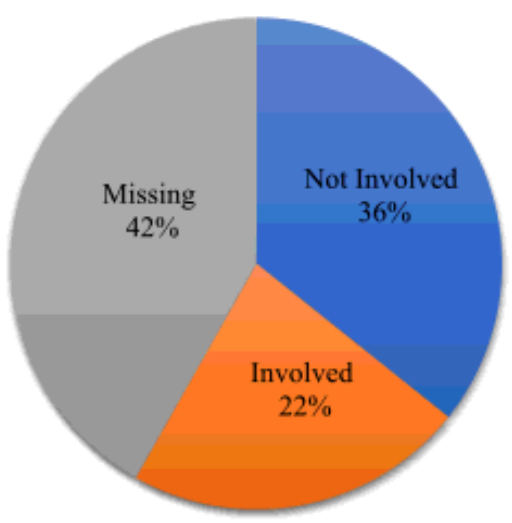

\section{Figure 7}

Disaster-related work experience distribution

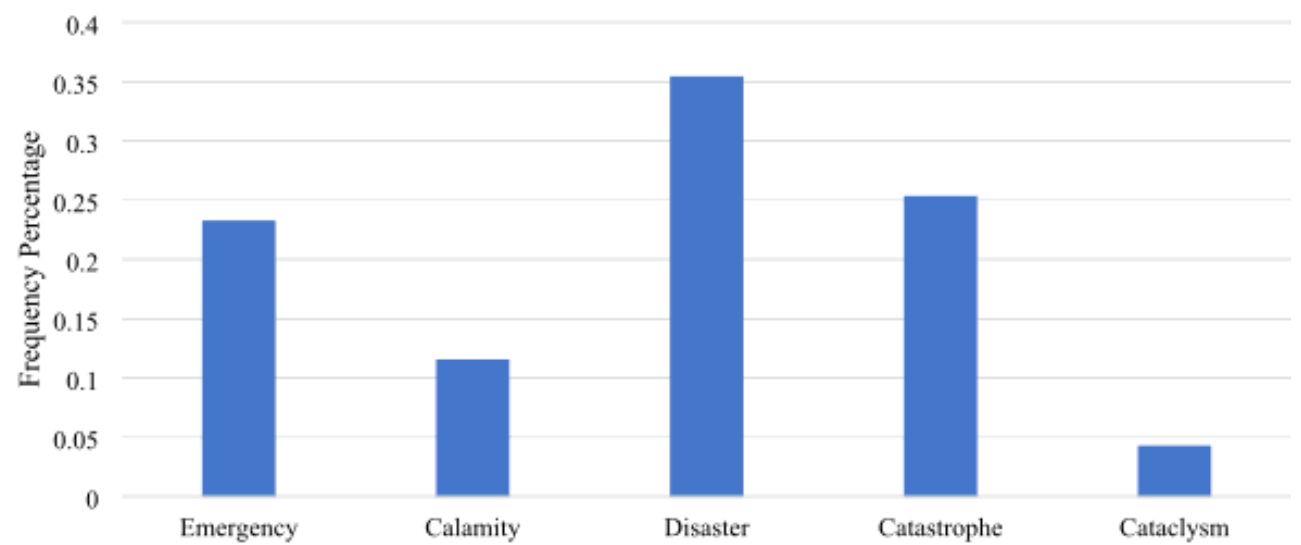

\section{Figure 8}

Frequency distribution of people's perception about the ongoing Covid-19 pandemic 
1.2

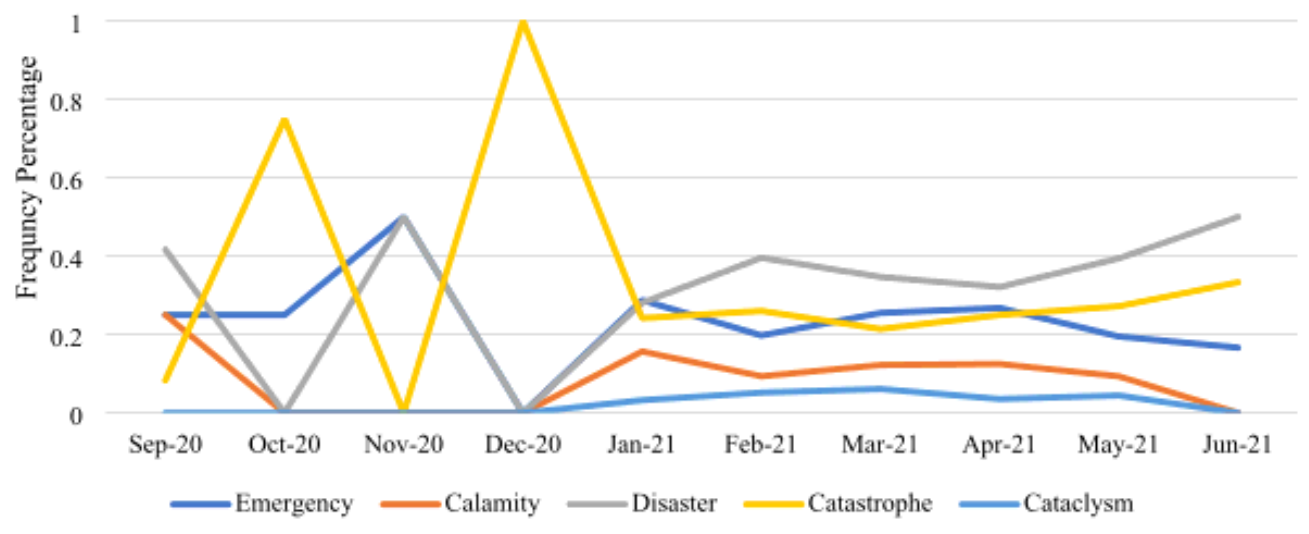

Figure 9

Change in perception about the ongoing Covid-19 pandemic

\section{Supplementary Files}

This is a list of supplementary files associated with this preprint. Click to download.

- Appendix.docx 